UNIVERSIDADE DE SÃO PAULO

FACULDADE DE ECONOMIA, ADMINISTRAÇÃO E CONTABILIDADE INSTITUTO DE PESQUISAS ECONÔMICAS PROGRAMA DE PÓS-GRADUAÇÃO EM ECONOMIA

EFEITOS DAS REFORMAS INSTITUCIONAIS NO SETOR BANCÁRIO SOBRE A PRODUTIVIDADE DOS BANCOS BRASILEIROS

Daniel Guilherme de Lima

Orientador: Prof. Dr. Márcio Issao Nakane

SÃO PAULO 
Prof. Dr. Marco Antonio Zago Reitor da Universidade de São Paulo

Prof. Dr. Aldalberto Américo Fischmann Diretor da Faculdade de Economia, Administração e Contabilidade

Prof. Dr. Hélio Nogueira da Cruz Chefe do Departamento de Economia

Prof. Dr. Márcio Issao Nakane Coordenador do Programa de Pós-Graduação em Economia 


\title{
EFEITOS DAS REFORMAS INSTITUCIONAIS NO SETOR BANCÁRIO SOBRE A PRODUTIVIDADE DOS BANCOS BRASILEIROS
}

\author{
Dissertação apresentada ao Programa de Pós- \\ Graduação do Departamento de Economia da \\ Faculdade de Economia, Administração e \\ Contabilidade da Universidade de São Paulo \\ como requisito parcial para a obtenção do \\ título de Mestre em Ciências.
}

Orientador: Prof. Dr. Márcio Issao Nakane

\author{
Versão Corrigida
}

(versão original disponível na Faculdade de Economia, Administração e Contabilidade)

\section{SÃO PAULO}


Lima, Daniel Guilherme de

Efeitos das Reformas Institucionais no Setor Bancário sobre a Produtividade dos Bancos Brasileiros/Daniel Guilherme de Lima. - São Paulo, 2016.

$41 \mathrm{p}$.

Dissertação (Mestrado) - Universidade de São Paulo, 2016.

Orientador: Márcio Issao Nakane.

1. Produtividade Total dos Fatores 2. Reformas Institucionais 3. Bancos I. Universidade de São Paulo. Faculdade de Economia, Administração e Contabilidade. II. Título.

$\mathrm{CDD}-332$ 
À minha família 
Agradeço ao meu orientador, Márcio Issao Nakane, pelo apoio na definição do tema, pelas reuniões em que discutíamos papers relacionados ao assunto e por todas as ideias que me foram bastante úteis na interpretação e análise dos resultados.

Além disso, gostaria de agradecer aos professores Fábio Adriano Miessi Sanches e Gabriel de Abreu Madeira pelas dicas e sugestões ao longo do desenvolvimento deste trabalho, contribuições estas que também foram muito importantes para transformar um esboço numa dissertação.

Por fim, sou bastante grato ao departamento de Economia da Faculdade de Economia, Administração e Contabilidade da Universidade de São Paulo por toda atenção ao longo desses últimos anos e também pela bolsa de estudos de mestrado. 
"Productivity and the growth of productivity must be the first economic consideration at all times, not the last.

That is the source of technological innovation, jobs, and wealth."

William E. Simon 


\section{RESUMO}

Este trabalho visa estudar a evolução da produtividade dos bancos brasileiros ao longo dos anos de 2000 a 2014, analisando o período pré e pós 2003, quando iniciou-se a introdução de reformas institucionais que afetaram o setor bancário, dando base à sustentabilidade do crescimento do crédito na economia e fortalecendo a estrutura das operações tanto à pessoa física quanto à pessoa jurídica. O estudo é introduzido através da estimação de funções de produção e obtenção de medidas de produtividade total dos fatores (PTF) para 86 bancos individuais, empregando as técnicas de Levinsohn e Petrin (2003) e de Ackerberg, Caves e Frazer (2015) para controlar problemas de endogeneidade e colinearidade que surgem por conta da variável não observada (produtividade) e da escolha dos insumos. Os bancos foram divididos em três grupos: (i) intensivos em operações de crédito, utilizando como critério a razão de operações de crédito/total do ativo maior ou igual a $50 \%$ no período anterior às reformas; (ii) não intensivos em operações de crédito, reunindo bancos com a razão anteriormente mencionada menor que $10 \%$, tendo como premissa que esse conjunto não é afetado diretamente pelas reformas; e (iii) os cinco maiores bancos do sistema financeiro brasileiro em relação ao ativo total. Os resultados mostram que (i) a produtividade agregada dos bancos oscilava sem direção definida no período anterior às reformas, mas mostraram um crescimento após as reformas; (ii) bancos intensivos em operações de crédito apresentaram ganho de produtividade de $7,0 \%$ a.a. após as reformas, totalizando $110,7 \%$ no período de 2004 a 2014, o que representa um crescimento bem mais expressivo que os 4,3\% a.a. para os bancos não intensivos, totalizando ganho de $58,9 \%$ após as reformas; e (iii) maior realocação do produto de bancos menos produtivos para bancos mais produtivos durante a crise financeira mundial de 2008.

Palavras-Chave: Produtividade Total dos Fatores. Reformas Institucionais. Bancos. 


\begin{abstract}
This paper aims to study the productivity of Brazilian banks from 2000 to 2014, analyzing the period before and after 2003, when began the introduction of institutional reforms affecting the banking sector, supporting the sustainability of credit growth in the economy and strengthening the structure of operations both to individuals as to legal entities. The study is introduced by estimating production functions and obtaining the total factor productivity (TFP) for 86 individual banks, implementing the methodology proposed by Levinsohn and Petrin (2003) and Ackerberg, Caves and Frazer (2015) to control problems of endogeneity and collinearity that arise due to the unobserved variable (productivity) and the choice of inputs. Banks were divided into three groups: (i) intensive in credit operations, using as criteria the ratio of credit operations/total assets greater than or equal to $50 \%$ in the period before the reforms; (ii) non-intensive in credit operations, bringing together banks with aforementioned ratio less than 10\%, with the assumption that this group is not directly affected by the reforms; and (iii) the five largest banks in the Brazilian financial system in relation to total assets. The results show that (i) the aggregate productivity of banks fluctuated without a defined direction in the period before the reforms, but showed growth after the reforms; (ii) intensive banks in credit operations showed productivity gains of $7.0 \%$ (compound annual growth rate) after the reforms, totaling 110.7\% from 2004 to 2014, which represents a much more significant growth than the 4.3\% per year for non-intensive banks, totaling a gain of 58.9\% after the reforms; and (iii) higher relocation of the product from less productive to more productive banks during the global financial crisis in 2008.
\end{abstract}

Keywords: Total Factor Productivity. Institutional Reforms. Banks. 


\section{SUMÁRIO}

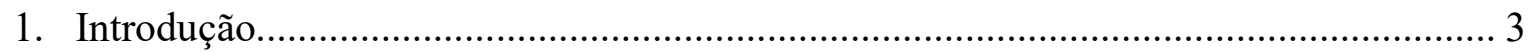

2. Revisão das reformas institucionais no setor bancário.............................................. 7

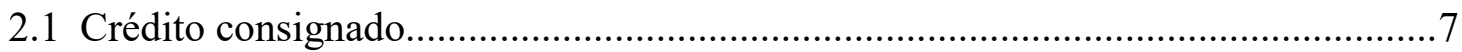

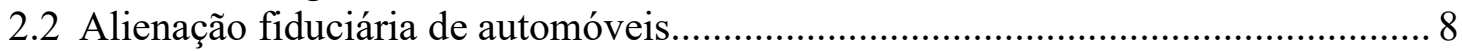

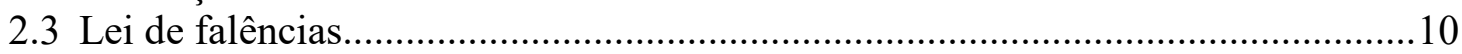

2.4 Sistema de Informações de Crédito do Banco Central (SCR)............................. 12

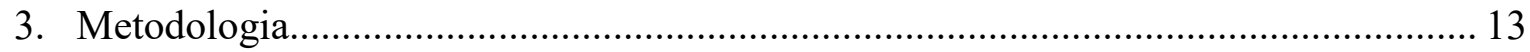

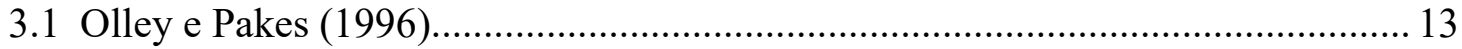

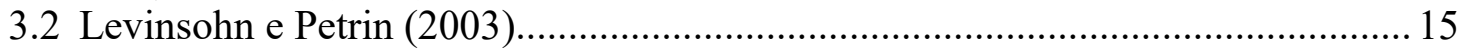

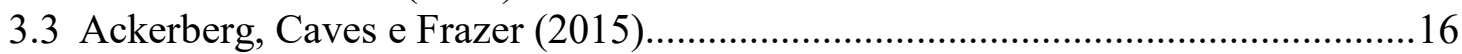

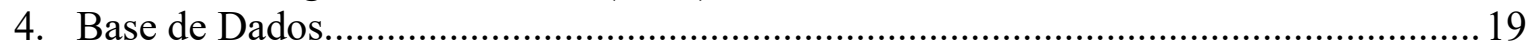

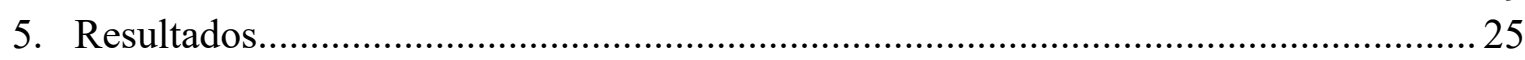

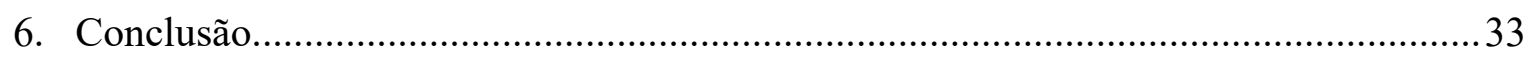

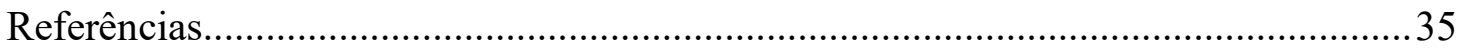

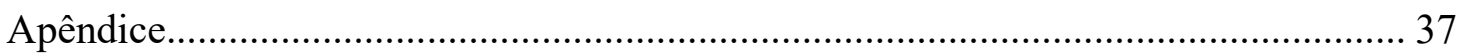

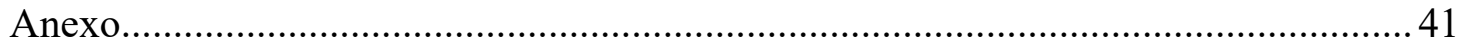





\section{INTRODUÇÃO}

A partir da primeira metade dos anos 2000, o setor bancário no Brasil passou por um amplo processo de transformação, influenciado tanto por fatores externos, com as inovações tecnológicas, quanto por fatores internos, com mudanças regulatórias e reformas microeconômicas, resultando no aumento da participação e da importância do crédito na estrutura econômica do país.

Segundo FREITAS e PRATES (2009), o contexto que favoreceu a expansão do crédito após 2003 foi a constatação de que não haveria alteração na política econômica do novo governo à época, além de um cenário de menor volatilidade macroeconômica e um contexto internacional favorável, tanto em relação ao setor de comércio exterior quanto às condições de liquidez para os países emergentes. Tais fatores teriam induzido os bancos a redefinir suas estratégias operacionais, priorizando o crédito.

O novo ambiente também foi protagonizado por algumas reformas microeconômicas, dando base para a expansão do mercado de crédito. Alguns exemplos são: a introdução do crédito consignado, a implementação da alienação fiduciária para financiamento de automóveis, a promulgação da nova lei de falências e o Sistema de Informação de Crédito, administrado pelo Banco Central do Brasil.

Esses avanços institucionais diminuíram os problemas decorrentes de seleção adversa e de risco moral, além de reduzir a insegurança jurídica e aumentar os direitos de propriedade dos credores, resultando em maior eficiência na concessão de crédito e menores taxas de juros, além de menor perda em caso de inadimplência e redução do risco de sua ocorrência.

Nesse novo contexto, aumentou-se a transparência das operações, tanto para os bancos como para os consumidores e empresas e, com isso, verificou-se um expressivo crescimento do crédito na economia, mais do que dobrando sua participação em relação ao PIB, passando do patamar de 24,3\% no início de 2004 para 58,9\% ao final de 2014 (vide gráfico 1).

Alguns estudos foram publicados analisando os efeitos das reformas no mercado de crédito para o tomador de empréstimo e para a economia. Segundo MADEIRA, RANGEL e RODRIGUES (2010), o crédito consignado, introduzido e regulamentado em dezembro de 2003, aumenta em 1,1 ponto percentual a escolha de o tomador se tornar empreendedor, o que significa um aumento de $20 \%$ dessa escolha, evidenciando um dos efeitos secundários positivos do aumento do crédito. 
Gráfico 1: Saldo da carteira de crédito em relação ao PIB (\%)

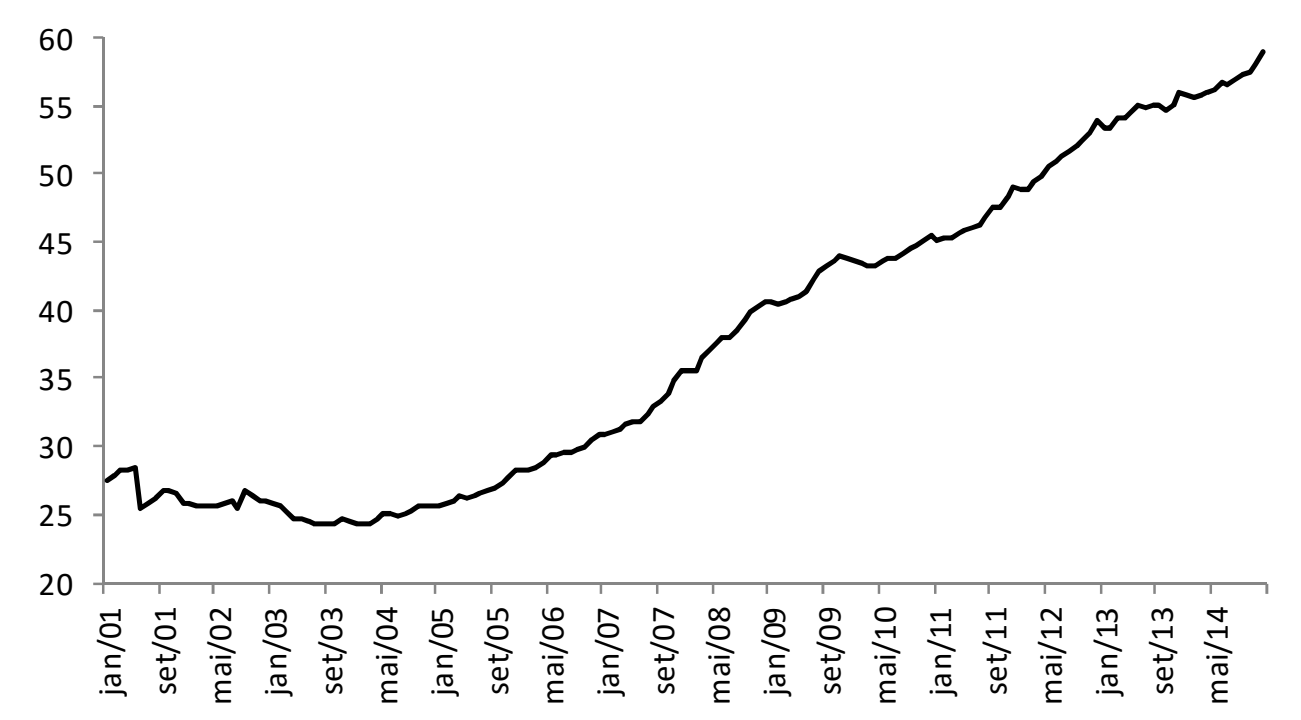

Fonte: Banco Central

Último dado: Dez/14

RODRIGUES, CHU, ALENCAR e TAKEDA (2006) avaliaram o impacto dessa nova modalidade de crédito nas taxas de juros bancárias associadas às pessoas que se endividavam tanto na modalidade tradicional de crédito pessoal como na de crédito consignado e encontraram evidências de que a introdução do crédito consignado reduziu significativamente essas taxas de juros.

Com respeito à alienação fiduciária de automóveis, implementada em agosto de 2004, o estudo feito por ASSUNÇÃO, BENMELECHE e SILVA (2012) constatou que as novas regras resultaram numa redução dos spreads e aumento do prazo dos empréstimos, além de expandirem o acesso ao crédito, incorporando pessoas antes excluídas por conta do seu maior grau de risco de inadimplência, movimento que os autores intitularam de "democratização do crédito".

A nova lei de falências, cujo início de vigência se dá em junho de 2005, diminuiu os incentivos a pedidos de concordata pelas empresas e, segundo ARAÚJO e FUNCHAL (2009), o número de falências (solicitadas e decretadas) foi reduzido por cerca da metade após a nova lei. Além disso, usando dados setoriais agregados de crédito, o estudo encontrou uma expansão do mercado de crédito, principalmente nos setores comerciais, rurais e de serviços.

Em outro estudo sobre esse mesmo tema, PONTICELLI (2012) testou o impacto da nova lei de falências sobre a produtividade das empresas e o seu acesso ao mercado de crédito. A análise incorporou as informações disponibilizadas pelo CNJ (Conselho Nacional de Justiça) que permitem formular indicadores de eficiência e agilidade das varas judiciais que tratam de casos de falência. O resultado mostrou que, após a nova lei, as firmas operando nas varas com 
maior eficiência tiveram um aumento significativamente maior do investimento e da produtividade, além de maior crescimento dos salários. Além disso, o estudo mostra que há evidência de que esse efeito decorre da maior utilização de recursos externos, como empréstimos, para financiar o investimento em novas tecnologias. Com isso, a maior confiança na qualidade das garantias de crédito teria permitido a sua expansão, com impacto positivo sobre a produtividade e o crescimento.

Essas reformas institucionais resultaram num novo quadro estrutural para o mercado de crédito, com influências diretas e indiretas para o sistema bancário, que também passou por profundas transformações na última década com o aumento da competição dentro e fora do setor, acirrada pela crise financeira de 2008, a entrada de bancos estrangeiros, o aumento no número das operações de fusão e aquisição, privatizações, mercados financeiros mais globalizados com fluxos de capitais mais voláteis e mudanças regulatórias.

NAKANE e WEINTRAUB (2005) avaliaram os impactos da privatização de bancos estatais sobre a produtividade através de medidas da produtividade total dos fatores (PTF) e constataram que bancos estatais são menos produtivos que bancos privados e que a privatização aumentou a produtividade. Para o procedimento de análise, os autores utilizaram a metodologia de Levinsohn e Petrin (2003), que controla a possível endogeneidade que pode ocorrer na função de produção, em que algum insumo pode estar correlacionado com a produtividade, gerando estimativas viesadas e não consistentes.

Para o propósito do estudo que será desenvolvido, um aspecto crucial para a análise é a separação dos bancos em um grupo intensivo e não intensivo em operações de crédito, considerando para este fim a métrica da razão da conta de operações de crédito/total do ativo.

Outros estudos na literatura econômica, como SOUZA-RODRIGUES (2009), avaliaram a evolução da produtividade bancária sob diferentes metodologias, mas sem segregar os bancos em grupos mais ou menos afetados por algum fator específico.

O estudo da produtividade dos bancos é relevante por esta ser uma medida resumo de desempenho, dado que mudanças na PTF refletem tanto inovações tecnológicas quanto alterações na eficiência, sendo, assim, útil tanto para uma melhor alocação dos investimentos quanto para a tomada de decisões de crescimento inorgânico, via fusões e aquisições.

Além disso, a importância do setor bancário para a economia e as evidências empíricas de que existe uma relação forte e positiva entre o nível de desenvolvimento financeiro e o crescimento econômico, como exposto em LEVINE e DEMIRGÜÇ-KUNT (2008), reforçam a motivação na escolha do tema em estudo, sendo que a avaliação da produtividade dos bancos também pode ser uma importante ferramenta para o Banco Central de qualquer país 
nas decisões de gestão e de política econômica, dado que baixa produtividade pode ser um sinal de alerta e, com isso, autoridades de supervisão bancária podem usar medidas de produtividade como um instrumento adicional de monitoramento.

Os resultados mostram que, de fato, houve uma aceleração do crescimento da produtividade para o grupo agregado dos bancos após as reformas, passando a ter um crescimento anual médio de 9,3\%, ante 5,8\% no período anterior, de 2000 a 2003.

Mais interessante ainda é notar que o desempenho da produtividade dos bancos intensivos em operações de crédito é superior ao observado para os bancos não intensivos após as reformas até a crise financeira de 2008/2009.

Por fim, este trabalho está estruturado iniciando com a apresentação das reformas, numa breve revisão acerca do crédito consignado, da alienação fiduciária de automóveis, da nova lei de falências e do sistema de informações de crédito do Banco Central.

Na seção seguinte, são discutidas algumas metodologias presentes na literatura econômica sobre a estimação e identificação dos coeficientes da função de produção, levando-se em consideração questões de endogeneidade e colinearidade dos insumos, o que, caso negligenciadas, poderiam gerar estimativas viesadas e inconsistentes dos parâmetros.

Após essa discussão é apresentada a base de dados que foi utilizada, usando como fonte dados públicos disponíveis no endereço eletrônico do Banco Central do Brasil, no sistema do Plano Contábil das Instituições do Sistema Financeiro Nacional (COSIF).

$\mathrm{Na}$ seção seguinte temos os resultados, fornecendo pistas bastante sugestivas para a conclusão de que os bancos intensivos em operações de crédito tiveram um ganho de produtividade maior que os bancos não intensivos no período pós reformas. 


\section{REVISÃO DAS REFORMAS INSTITUCIONAIS}

Esta seção destina-se a discorrer em um breve resumo as principais características das reformas institucionais ocorridas ao longo da primeira metade dos anos 2000, afetando o setor de crédito brasileiro e agindo no sentido de:

- Diminuir o risco de inadimplência nos empréstimos, com a implementação do crédito consignado.

- Reformular procedimentos de modo a melhorar a execução de garantias e reduzir a insegurança jurídica, com a introdução da alienação fiduciária de automóveis.

- Aumentar os diretos dos credores, com a aprovação da lei de falências.

- Reduzir a assimetria de informação, com o estabelecimento do Sistema de Informações de Crédito do Banco Central (SCR).

\subsection{Crédito consignado}

Introduzido em dezembro de 2003, o crédito consignado é a modalidade de empréstimo concedido a trabalhadores de empresas públicas, privadas, ou a aposentados em que o desconto da prestação é feito diretamente na folha de pagamento ou benefício previdenciário do cidadão.

No ato da contratação, o cliente deve autorizar por escrito a realização do débito mensal e para obter esse tipo de empréstimo o cliente deve se dirigir a bancos ou financeiras e o prazo de pagamento é de até 72 meses, sendo que os juros variam conforme o valor contratado.

No site do Ministério da Previdência Social (www.previdencia.gov.br) é possível acessar um documento com as taxas de juros praticadas por todos os bancos que disponibilizam esse tipo de empréstimo a aposentados e pensionistas. Para os demais clientes, as taxas são publicadas no endereço eletrônico do Banco Central (www.bcb.gov.br).

Além disso, há também a cobrança do Imposto sobre Operações Financeiras (IOF) e é proibida a cobrança de Taxa de Abertura de Crédito (TAC).

O crédito consignado é vantajoso tanto para quem o cede - pois a cobrança é automática e de responsabilidade da empresa do cliente, do sindicato ao qual ele pertence ou 
do governo - quanto para quem demanda o empréstimo, pois elimina a necessidade de quitar a dívida tendo que se deslocar a uma instituição financeira ou tendo que realizar o procedimento de pagamento via internet.

Com isso, pode-se dizer que as melhores garantias reduzem os problemas decorrentes de seleção adversa e de risco moral, resultando em maior eficiência na concessão de crédito e menores taxas de juros, tanto pela menor perda em caso de inadimplência, quanto pelo seu menor risco de ocorrência.

O gráfico 2 abaixo ilustra o vigoroso crescimento do crédito consignado desde a sua introdução, atingindo R $\$ 252$ bilhões ao final de 2014, ao mesmo tempo em que a taxa média de juros ao ano passou por um processo de expressiva queda, entre algumas oscilações, indo de 41,4\% a.a. em janeiro de 2004 para 25,9\% a.a. em dezembro de 2014.

Gráfico 2: Saldo de crédito consignado total e taxa média de juros

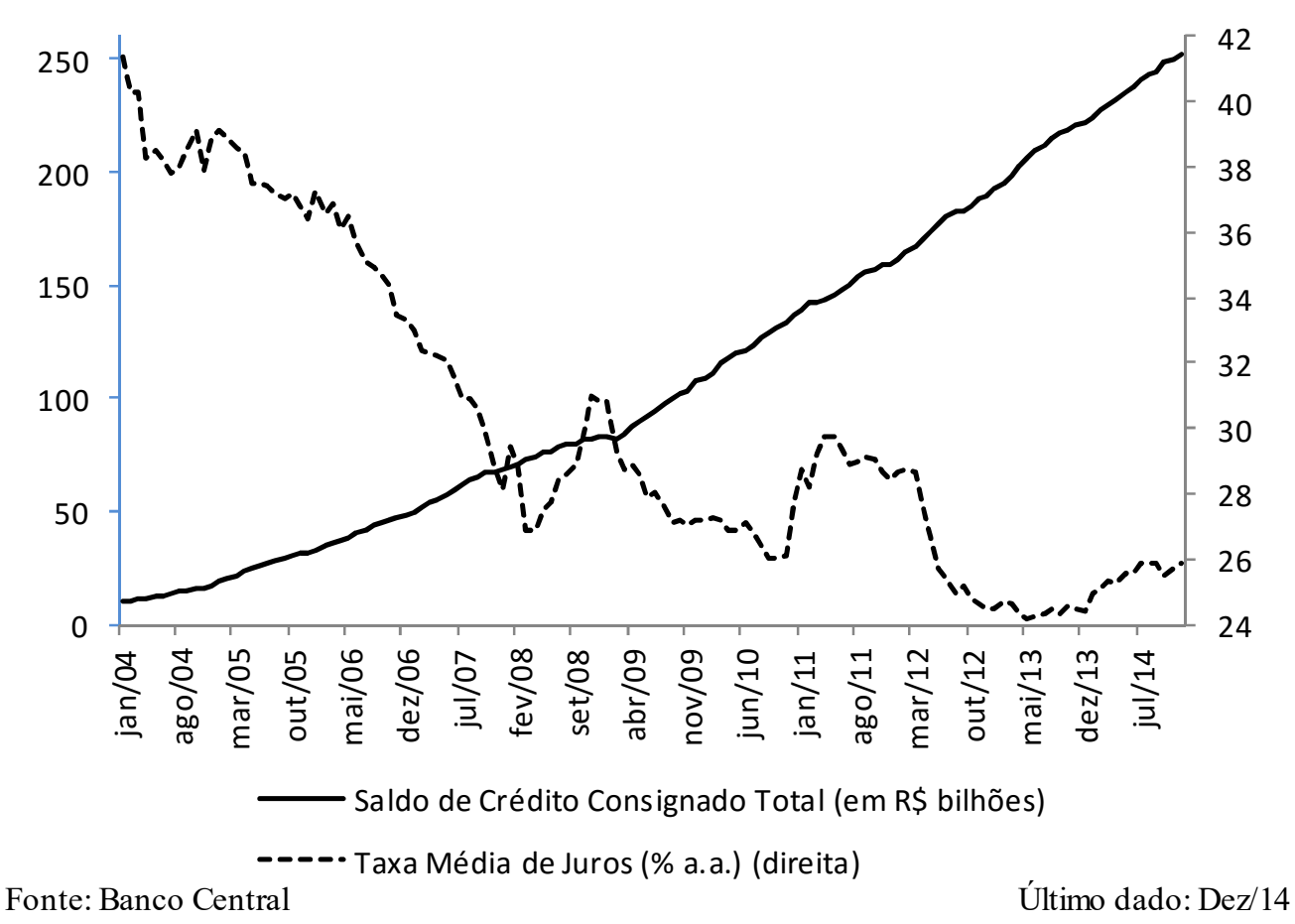

\subsection{Alienação fiduciária de automóveis}

A alienação fiduciária consiste na transferência da posse de um bem móvel ou imóvel do devedor ao credor para garantir o cumprimento de uma obrigação. O credor toma o próprio bem em garantia, de forma que o comprador pode usufruir do mesmo, no entanto, fica 
impedido de negociá-lo com terceiros. Sendo assim, a prática nada mais é que um direito real de garantia.

Antes da regulamentação desse procedimento para a aquisição de veículos, o mercado brasileiro de empréstimos para compra de automóveis enfrentava diversos obstáculos, dentre eles, o processo ineficiente de reintegração de posse e revenda dos automóveis quando da inadimplência dos mutuários.

Os bancos podiam reaver os automóveis de devedores inadimplentes, no entanto, os veículos não podiam ser revendidos sem a aprovação da justiça e, como resultado, o tempo entre a reintegração de posse até a revenda do automóvel pelo banco levava em média mais de 2 anos, gerando prejuízo aos bancos dada a perda de valor do automóvel ao longo desse período até a efetiva revenda.

Com isso, para remover as ineficiências nos empréstimos para compra de automóveis, em agosto de 2004, o governo promulgou a lei de alienação fiduciária, afetando diretamente o mercado em questão, ampliando consideravelmente o volume da carteira de crédito para aquisição de veículos (vide gráfico 3).

A mudança mais notável introduzida pela lei e que se aplica aos empréstimos para compra de automóveis foi no sentido de facilitar a autorização para a revenda de um veículo após a reintegração de posse pelo banco, tornando o processo mais simples e rápido.

AMENDOLARA (2006) destacou 3 diferenças em relação ao processo de reintegração de posse e revenda:

- Logo após o banco receber um mandado judicial para apreender o automóvel, o mutuário tem um prazo de 5 dias para quitar a dívida e recuperar a posse do veículo.

- O mutuário passa a ter 15 dias para contestar a liminar judicial, em vez dos 3 dias anteriormente estabelecidos. A principal diferença na lei é que agora o banco pode revender o carro após este período de 15 dias, sendo que anteriormente a venda só poderia ocorrer após a aprovação de um tribunal, o que era custoso para o banco por conta da burocracia e da desvalorização do automóvel ao longo do tempo.

- O mutuário tem o direito de contestar o banco em tribunal. Se o banco for considerado culpado, o mutuário deve ser compensado por um montante igual a $150 \%$ do total do empréstimo.

Com isso, a lei reformulou a relação dos devedores, credores e tribunais ao aumentar a eficiência na execução de garantias, induzindo os bancos a ofertarem mais empréstimos com menores spreads e prazos mais longos e, além disso, a redução na insegurança jurídica ampliou o acesso ao crédito para pessoas com menor renda e maior risco de inadimplência, 
público anteriormente excluído desse mercado, resultando numa "democratização" do crédito (ASSUNÇÃO, BENMELECH E SILVA, 2012).

O gráfico 3 abaixo mostra a evolução da carteira de crédito para aquisição de veículos, passando de R \$ 34,7 bilhões em agosto de 2004 para R\$ 184,2 bilhões em dezembro de 2014. Vale destacar que a média de janeiro de 2001 a julho de 2004 não passa de R $\$ 27$ bilhões.

Gráfico 3: Saldo da carteira de crédito para aquisição de veículos

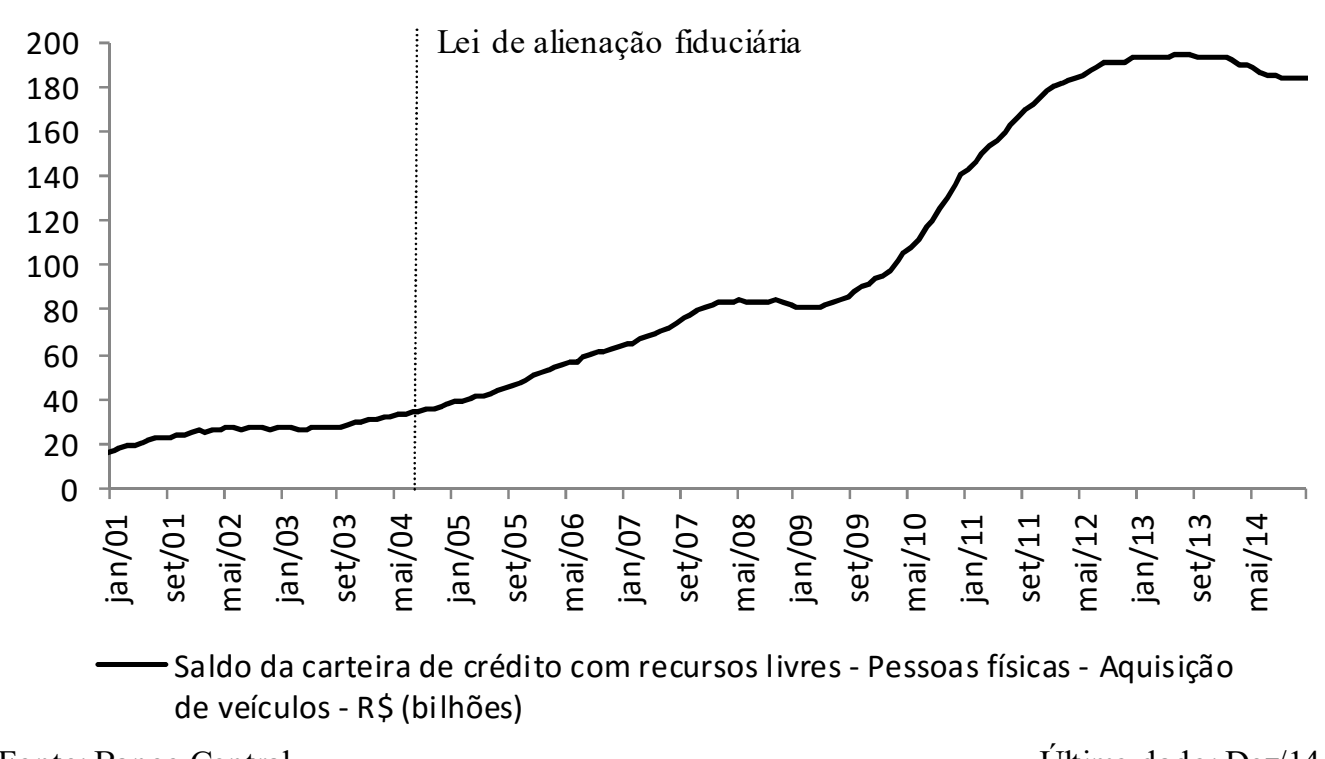

Fonte: Banco Central

Último dado: Dez/14

\subsection{Lei de falências}

A velha lei de falências foi estabelecida em 1945, estabelecendo que, uma vez que uma firma fosse fechada, uma trustee seria apontada por um tribunal judicial como a responsável por avaliar e organizar a venda dos ativos da firma. Os ativos seriam vendidos aos poucos e as receitas seriam distribuídas entre os demandantes de acordo com a seguinte regra de prioridade:

- Salários não pagos dos trabalhadores

- Impostos devidos ao governo

- Empréstimos garantidos

- Empréstimos não garantidos e fornecedores

- Acionistas 
Se uma firma enfrentasse problemas de liquidez em vez de problemas de insolvência uma alternativa legal à insolvência era a recuperação judicial, chamada "concordata" com a qual um juiz autorizava a firma a reestruturar suas dívidas de acordo com uma agenda de pagamentos específica, no entanto, esse procedimento não era flexível o suficiente para atender aos interesses da firma, pois era estabelecida uma agenda rígida de pagamento para os dois anos seguintes, com muito pouca margem de adaptação para situações específicas. Além disso, cobriam-se apenas dívidas com fornecedores, não incluindo empréstimos garantidos e não garantidos na reestruturação, portanto, a concordata não era muito adequada para a recuperação de firmas produtivas com problemas de liquidez temporários.

Em junho de 2005 foi estabelecida a nova lei de falências e as duas mudanças mais importantes foram a introdução de um novo procedimento de recuperação judicial e extrajudicial e uma nova regra de prioridade.

Em vez de haver o sistema rígido da concordata para recuperar a firma, o juiz apenas supervisiona o processo de barganha entre os demandantes que eventualmente definem o plano de ação e a divisão do valor da firma, valendo destacar que o plano de ação é executado logo após a aprovação pela maioria dos demandantes, que são divididos em classes dependendo do tipo de crédito eles concederam. Além disso, durante esse processo a firma não é fechada e sim dirigida por uma trustee.

A recuperação extrajudicial é similar à judicial, mas sem a necessidade da presença do juiz no começo do processo, sendo que, se a firma e os credores chegarem a um acordo informal o juiz posteriormente apenas sanciona o plano, desde que este esteja dentro legalidade.

Quanto à nova regra de prioridade, empréstimos garantidos têm preferência aos impostos devidos ao governo, mas prioridade menor que os salários não pagos.

A nova lei de falências aumentou a proteção aos direitos de propriedade dos investidores e, por esses direitos serem fundamentais no desenvolvimento do sistema financeiro é razoável esperar que os bancos fiquem mais dispostos a emprestar para dado nível de insumos (SOUZA-RODRIGUES, 2009). FUNCHAL (2008) documenta que o custo de capital para as empresas caiu em média $22 \%$, enquanto o crédito aumentou $39 \%$, sendo 79\% nas operações de longo prazo.

Por fim, a nova lei de falências fez com que as empresas em dificuldades passassem a ser incentivadas a seguir um processo de negociação com seus credores, o que reduziu os incentivos a pedidos de concordata. 
O gráfico 4 mostra a evolução do volume de falências requeridas e decretadas antes e após o estabelecimento da nova lei de falências. É evidente a queda brusca no número de falências requeridas e a estabilização das falências decretadas em um patamar inferior ao que era verificado no período anterior à promulgação dessa nova lei.

Gráfico 4: Volume de falências requeridas X decretadas

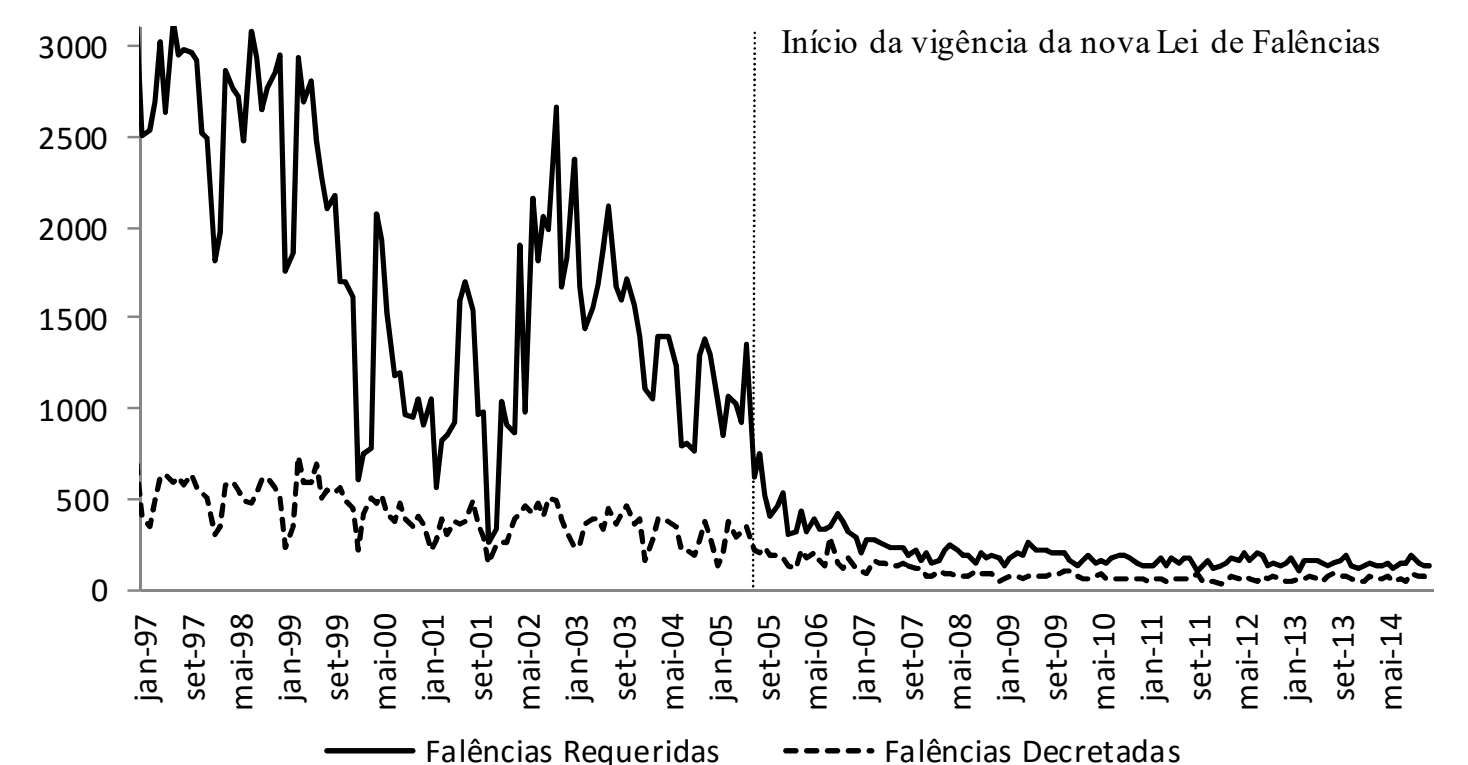

Fonte: Serasa Experian

Último dado: Dez/14

\subsection{Sistema de Informações de Crédito do Banco Central (SCR)}

De acordo com a própria definição do Banco Central, o Sistema de Informações de Crédito (SCR) é um banco de dados sobre operações e títulos com características de crédito e respectivas garantias contratados por pessoas físicas e jurídicas perante instituições financeiras no País. O SCR é alimentado mensalmente pelas instituições financeiras, mediante coleta de informações sobre as operações concedidas.

Apesar de o Sistema de Informações de Crédito (SCR) ter sido formulado e implementado em 1999 com fins de supervisão, o sistema foi reestruturado e o novo SCR foi estabelecido em julho de 2004, com a principal diferença de que agora o sistema contém informação detalhada fornecida pelos bancos todo o mês e informações consolidadas sobre suas operações de crédito. Com isso, reduz-se a assimetria de informação e os bancos conseguem avaliar de uma melhor maneira o risco do crédito. 


\section{METODOLOGIA}

A seguir são apresentadas algumas das principais discussões e metodologias presentes na literatura econômica quanto à formulação de modelos econométricos para a estimação de funções de produção e análise da evolução da produtividade.

Cada metodologia após Olley e Pakes adiciona uma nova ideia para estimar os parâmetros da função de produção de forma consistente, enriquecendo o debate com respeito ao viés de endogeneidade que a variável não observável produtividade pode gerar e também ao se levar em conta o potencial problema de identificação e correlação nos erros.

\subsection{Olley e Pakes (1996)}

Mudanças tecnológicas e o processo gradual de liberalização no ambiente regulatório causaram uma grande reestruturação na indústria de equipamentos de telecomunicações nos Estados Unidos nos anos 70 e 80 e, dado esse fato, o foco empírico do estudo promovido pelos autores foi a estimação dos parâmetros da função de produção dessa indústria para análise da dinâmica da produtividade.

Para ilustrar a ideia geral do procedimento adotado na estimação da função de produção, segue-se a linha do exposto em Levinsohn e Petrin (2003) e em Ackerberg, Caves e Frazer (2015), simplificando levemente o modelo e tomando a função de produção CobbDouglas em logs como:

$$
y_{i t}=\beta_{l} l_{i t}+\beta_{k} k_{i t}+\omega_{i t}+\varepsilon_{i t}
$$

em que $y_{i t}$ é o log da produção da firma i no período t, $l_{i t}$ é o log do insumo trabalho, $k_{i t}$ é o $\log$ do insumo capital, $\omega_{i t}$ é o $\log$ da produtividade e $\varepsilon_{i t}$ é um componente de choque i.i.d.

Agrupamos o termo constante na função de produção dentro do termo produtividade. Tanto $\omega_{i t}$ quanto $\varepsilon_{i t}$ não são observáveis para o econometrista e a diferença entre as duas variáveis é que a primeira é uma variável de estado e, assim, impacta as regras de decisão da firma enquanto a segunda não tem essa implicação.

Olley e Pakes (OP) tomam o investimento como uma função da produtividade e do capital:

$$
i_{i t}=f_{t}\left(\omega_{i t}, k_{i t}\right)
$$


Assume-se que o investimento é uma função crescente da variável não observável produtividade e a monotonicidade implica que a função acima pode ser invertida para gerar uma equação que deixa a produtividade em função de variáveis observáveis:

$$
\omega_{i t}=f_{t}^{-1}\left(i_{i t}, k_{i t}\right)
$$

Substitui-se em (1):

$$
y_{i t}=\beta_{l} l_{i t}+\phi_{t}\left(i_{i t}, k_{i t}\right)+\varepsilon_{i t}
$$

em que:

$$
\phi_{t}\left(i_{i t}, k_{i t}\right)=\beta_{k} k_{i t}+f_{t}^{-1}\left(i_{i t}, k_{i t}\right)
$$

Na primeira etapa, um estimador que é linear em $l_{t}$ e não paramétrico em $\phi_{t}$ pode ser usado para obter uma estimativa para $\beta_{l}$ e para o termo composto $\phi_{t}\left(i_{i t}, k_{i t}\right)$. Após isso, OP usam uma aproximação de $4^{\mathrm{a}}$ ordem em $i_{i t}$ e $k_{i t}$ para aproximar $\phi_{t}$, estimando (2) usando OLS.

Para evitar as complicações do procedimento acima e explorar mais o lado não paramétrico da equação (2), a segunda etapa pode seguir o seguinte procedimento:

OP assumem que $\omega_{i t}$ segue um processo de Markov de primeira ordem, ou seja:

$$
E\left[\omega_{i t+1} \mid I_{i t}\right]=E\left[\omega_{i t+1} \mid \omega_{i t}\right]
$$

sendo $I_{i t}$ o conjunto de informação da firma i no período t. As expectativas da firma sobre a produtividade futura, $\omega_{i t+1}$, dependem apenas da produtividade presente, $\omega_{i t}$.

Com isso, podemos escrever:

$$
\omega_{i t}=E\left[\omega_{i t} \mid I_{i t-1}\right]+\xi_{i t}=E\left[\omega_{i t} \mid \omega_{i t-1}\right]+\xi_{i t}
$$

sendo $\xi_{i t}$ a inovação em $\omega_{i t}$, sendo que, pela propriedade da esperança condicional

$$
E\left[\xi_{i t} \mid I_{i t-1}\right]=0
$$

Tomando a propriedade acima juntamente com o pressuposto temporal de que o capital, $k_{i t}$, é decido em t-1, temos que $\xi_{i t}$ é ortogonal a $k_{i t}$, ou seja:

$$
E\left[\xi_{i t} \mid k_{i t}\right]=0
$$

o que implica que $\xi_{i t}$ e $k_{i t}$ são não correlacionados, ou seja:

$$
E\left[\xi_{i t} k_{i t}\right]=0
$$

esse é o momento que OP usam para identificar o coeficiente do capital, $\beta_{k}$.

Para operacionalizar esse procedimento num contexto de GMM, note que, dado um palpite sobre $\beta_{k}$, pode-se inverter os $\omega_{i t}$ s em todos os períodos, ou seja:

$$
\omega_{i t}\left(\beta_{k}\right)=\hat{\phi}_{i t}-\beta_{k} k_{i t}
$$

Dados esses $\omega_{i t}\left(\beta_{k}\right)$ 's, pode-se computar $\xi_{i t}$ 's em todos os períodos ao regredir não parametricamente $\omega_{i t}\left(\beta_{k}\right)$ 's em $\omega_{i t-1}\left(\beta_{k}\right)$ 's (e um termo constante) e formar o resíduo: 


$$
\xi_{i t}\left(\beta_{k}\right)=\omega_{i t}\left(\beta_{k}\right)-\hat{\psi}\left(\omega_{i t-1}\left(\beta_{k}\right)\right)
$$

em que $\hat{\psi}\left(\omega_{i t-1}\left(\beta_{k}\right)\right)$ são os valores previstos da regressão não paramétrica.

Esses $\xi_{i t}\left(\beta_{k}\right)$ 's podem então ser usados para formar um análogo de amostra para o momento acima, $E\left[\xi_{i t} k_{i t}\right]=0$, isto é:

$$
\frac{1}{T} \frac{1}{N} \sum_{t} \sum_{i} \xi_{i t}\left(\beta_{k}\right) * k_{i t}
$$

Num procedimento GMM, $\beta_{k}$ é estimado ao aproximar o resultado acima o mais próximo possível de zero.

\subsection{Levinsohn e Petrin (2003)}

A abordagem de Levinsohn e Petrin (LP) é uma extensão do método discutido acima, sendo que os autores chamam atenção para o fato de que o investimento é custoso para se ajustar e esse custo de ajustamento pode resultar em um investimento não contínuo e as observações de investimento zero farão com que a condição de monotonicidade não prevaleça para esses casos, impedindo que a função de investimento seja invertida para deixar a variável não observável produtividade em função de variáveis observáveis.

Para contornar esse problema, os autores sugerem usar um insumo intermediário em vez do investimento, garantido que o insumo intermediário seja estritamente crescente na produtividade. Com isso, temos a nova função de produção:

$$
y_{i t}=\beta_{l} l_{i t}+\beta_{k} k_{i t}+\beta_{m} m_{i t}+\omega_{i t}+\varepsilon_{i t}
$$

A função de demanda para o insumo intermediário é dada por:

$$
m_{i t}=f_{t}\left(\omega_{i t}, k_{i t}\right)
$$

e deve ser monotônica em $\omega_{i t}$ para todo $k_{i t}$ para se qualificar como uma proxy válida.

Assumindo que monotonicidade vale, podemos inverter a função de demanda para o insumo intermediário para obter $\omega_{i t}=f_{t}^{-1}\left(m_{i t}, k_{i t}\right)$, assim, o insumo intermediário substitui o investimento, com $\phi_{t}($.$) agora sendo uma função de m_{i t} \mathrm{e} k_{i t}$ :

$$
\phi_{t}\left(m_{i t}, k_{i t}\right)=\beta_{k} k_{i t}+\beta_{m} m_{i t}+f_{t}^{-1}\left(m_{i t}, k_{i t}\right)
$$

Daí segue-se da mesma maneira que em OP.

A primeira etapa consiste em obter estimativas de $\beta_{l}$ e do termo composto, $\phi_{t}$.

A segunda etapa é similar ao método anterior, sendo que a única diferença é que há um parâmetro a mais para estimar, $\beta_{m}$. 
LP usam a mesma condição de momento que OP para identificar o coeficiente do capital, isto é, que o componente de inovação, $\xi_{i t}$, é ortogonal a $k_{i t}$.

$\xi_{i t}\left(\beta_{k}, \beta_{m}\right)$ pode novamente ser construído como o resíduo de uma função não paramétrica de $\omega_{i t}\left(\beta_{k}, \beta_{m}\right)$ 's em $\omega_{i t-1}\left(\beta_{k}, \beta_{m}\right)$ 's .

Eles também adicionam um momento adicional para identificar $\beta_{m}$, a condição de que $\xi_{i t}\left(\beta_{k}, \beta_{m}\right)$ é ortogonal a $m_{i t-1}$. Disso, temos a seguinte condição de momento na qual se dá a base da estimação:

$$
E\left[\left.\xi_{i t}\left(\beta_{k}, \beta_{m}\right)\right|_{m_{i t-1}} ^{k_{i t}}\right]=0
$$

\subsection{Ackerberg, Caves e Frazer (2015)}

O estudo desses autores examina a fundo o papel da identificação de funções de produção, focando nas técnicas sugeridas nas duas abordagens discutidas anteriormente e argumentando que essas metodologias, particularmente as de LP, sofrem de problemas de colinearidade.

Considerando as técnicas de LP, temos que, como o modelo assume que o trabalho e o insumo intermediário são escolhidos simultaneamente e ambos são perfeitamente variáveis e insumos não dinâmicos, um pressuposto natural pode ser que eles são decididos de maneira similar.

Sendo $m_{i t}$ o insumo intermediário e escolhido de acordo com:

$$
m_{i t}=f_{t}\left(\omega_{i t}, k_{i t}\right)
$$

Temos que isso sugere que $l_{i t}$ pode ser escolhido de acordo com:

$$
l_{i t}=g_{t}\left(\omega_{i t}, k_{i t}\right)
$$

Enquanto $g_{t}$ será uma função tipicamente diferente de $f_{t}$ elas geralmente dependerão das mesmas variáveis estado, $\omega_{i t}$ e $k_{i t}$.

Lembrando que $\omega_{i t}=f^{-1}\left(m_{i t}, k_{i t}\right)$, substituímos essa equação em (10), gerando:

$$
l_{i t}=g_{t}\left(f^{-1}\left(m_{i t}, k_{i t}\right), k_{i t}\right)=h_{t}\left(m_{i t}, k_{i t}\right)
$$

que estabelece que $l_{i t}$ é uma função variante no tempo de $m_{i t}$ e $k_{i t}$.

Isso tem implicações bastante fortes no primeiro estágio da estimação da função de produção, pois, dada a perfeita colinearidade entre $l_{i t}$ e os termos da função não paramétrica, o coeficiente $\beta_{l}$ não é identificado nesse primeiro estágio. 
ACF providenciam uma discussão detalhada sobre qual mecanismo de geração de dados seria razoável para assumir e que ainda seria capaz de identificar os parâmetros da função de produção. Infelizmente, os mecanismos analisados não são muito convincentes ou acabam tendo que assumir pressupostos muito fortes e, por essa razão, os autores propuseram um método alternativo que abre mão de tentar estimar $\beta_{m}$ e $\beta_{l}$ no primeiro estágio.

Os autores supõem que o insumo trabalho, $l_{i t}$, é escolhido depois de $k_{i t}$, mas antes de $m_{i t}$. Eles acreditam que o trabalho é um insumo "menos variável" que os insumos intermediários, pois as firmas precisam de tempo para treinar novos trabalhadores ou precisam dar algum aviso prévio antes de demiti-los. Isso soa particularmente verdadeiro para o mercado brasileiro, pois é consenso que as realocações do insumo trabalho são muito custosas devido à rígida legislação do mercado de trabalho.

Dados esses pressupostos temporais, a demanda para o insumo intermediário da firma no período t dependerá diretamente de $l_{i t}$, que é escolhido antes de $m_{i t}$.

$$
m_{i t}=f_{t}\left(\omega_{i t}, k_{i t}, l_{i t}\right)
$$

Invertendo essa função para $\omega_{i t}$ e substituindo na função de produção chega-se na equação do primeiro estágio:

$$
y_{i t}=\beta_{l} l_{i t}+\beta_{k} k_{i t}+f_{t}^{-1}\left(m_{i t}, k_{i t}, l_{i t}\right)+\varepsilon_{i t}
$$

Desta vez, $\beta_{l}$ é claramente não identificado no primeiro estágio, no entanto, pode-se obter uma estimativa do termo composto:

$$
\phi_{t}\left(m_{i t}, k_{i t}, l_{i t}\right)=\beta_{k} k_{i t}+\beta_{l} l_{i t}+f_{t}^{-1}\left(m_{i t}, k_{i t}, l_{i t}\right)
$$

Para identificar $\beta_{k}$ e $\beta$, precisamos de duas condições de momento independentes para identificação no segundo estágio.

Como na metodologia anterior, tomando como pressuposto que $\omega_{i t}$ segue um processo de Markov de primeira ordem, temos:

$$
\omega_{i t}=E\left[\omega_{i t} \mid I_{i t-1}\right]+\xi_{i t}=E\left[\omega_{i t} \mid \omega_{i t-1}\right]+\xi_{i t}
$$

em que $\xi_{i t}$ é média independente de toda informação em t-1.

Dado o pressuposto temporal usado em OP/LP de que $k_{i t}$ é decidido em t-1, temos a condição de momento do segundo estágio:

$$
E\left[\xi_{i t} \mid k_{i t}\right]=0
$$

Como $l_{i t}$ é escolhido após t-1, será geralmente correlacionado com pelo menos parte de $\xi_{i t .}$ Por outro lado, $l_{i t-1}$ não terá esse problema. Sendo assim, temos:

$$
E\left[\xi_{i t} \mid{ }_{l_{i t-1}}^{k_{i t}}\right]=0
$$


Esses são os dois momentos que os autores sugerem na estimação para identificar $\beta_{k} \mathrm{e}$ $\beta$.

Vale destacar que ACF apresentam uma discussão acerca da relação das técnicas sugeridas por eles com os modelos dinâmicos de painel. Os autores argumentam que há algumas vantagens do estimador dinâmico de painel sobre o estimador estudado em ACF, sendo que a mais importante delas é a possibilidade de permitir efeitos fixos e também que painéis dinâmicos requerem menos pressupostos em relação às equações de demanda de insumos.

Por outro lado, permitir efeitos fixos exige uma diferenciação adicional e mais defasagens de instrumentos, sendo, talvez, essa a razão sobre porquê algumas vezes esses estimadores não têm funcionado particularmente bem na prática.

Após essa revisão das principais metodologias empregadas na literatura com relação ao tema em estudo, temos que a parte empírica deste trabalho iniciará com a estimação de uma função de produção Cobb-Douglas tendo uma medida de produção bancária como variável dependente e alguns insumos produtivos, detalhados na seção Base de Dados.

Uma vez estimados os coeficientes da função de produção, o log da produtividade total dos fatores é computado pela diferença entre a produção atual e a produção calculada:

$$
\hat{\omega}_{t}=y_{i t}-\hat{\beta}_{k} k_{i t}-\hat{\beta}_{l} l_{i t}
$$




\section{BASE DE DADOS}

Para a realização do estudo são utilizados dados individuais de bancos, disponíveis no diretório eletrônico do Banco Central do Brasil, através do sistema do Plano Contábil das Instituições do Sistema Financeiro Nacional (COSIF), no qual as instituições financeiras do país divulgam seus dados contábeis periodicamente.

São consideradas as apurações dos balanços de março, junho, setembro e dezembro de cada ano, no período de março de 2000 a dezembro de 2014, focando na evolução da produtividade após 2004, dado que a primeira reforma institucional considerada, a introdução do crédito do consignado, aconteceu ao final de 2003.

A tabela 1 abaixo classifica os insumos e o produto que são utilizados no estudo.

Tabela 1: Descrição de insumos e produto

Insumos

Código COSIF

Capital

Imóveis de uso

22300001

Instalações, móveis e equipamentos de uso

22400004

Outros

22900009

Trabalho

Número total de empregados

Insumos Intermediários

Despesas Administrativas

\section{Produto}

Ativo Circulante e Realizável a Longo Prazo

10000007

Disponibilidades

11000006

Aplicações Interfinanceiras De Liquidez

12000005

Títulos e Valores Mobiliários e Instr. Financeiros Derivativos

13000004

Relações Interfinanceiras

14000003

Relações Interdependências

15000002

Operações De Crédito

16000001

Operações De Arrendamento Mercantil

17000000

Outros Créditos

18000009

Outros Valores E Bens

19000008 
Antes de iniciar a discussão sobre a base de dados vale destacar que não há um consenso na literatura acerca da definição de produto e insumo para os bancos. Além disso, alguns estudos empíricos usam depósitos bancários tanto como produto quanto insumo da atividade bancária. No entanto, devido à relevância dos depósitos bancários no lado do passivo no balanço do banco, a inclusão dos depósitos causaria um problema sério na estimativa da função de produção devido à identidade contábil que iguala ativo com passivo mais patrimônio líquido. No presente estudo, portanto, os depósitos bancários não são incluídos no processo de produção do banco.

O insumo trabalho e o insumo intermediário (líquido de despesas de pessoal) não estão disponíveis no sistema COSIF, mas os dados obtidos são também do Banco Central, disponíveis mediante requerimento no Sistema de Acesso à Informação e no também pelo IF Data e na seção dos "50 maiores bancos e o consolidado do Sistema Financeiro Nacional", disponíveis publicamente no endereço do Banco Central na internet (www.bcb.gov.br).

Despesas administrativas são líquidas de despesas de pessoal e englobam como principais itens as despesas de água, energia e gás, aluguéis, comunicações e processamentos de dados.

Importante ressaltar que os dados de despesas administrativas são apresentados de forma acumulada nos meses de fim de semestre, sendo assim, para se obter o valor do trimestre terminado em junho e dezembro basta subtrair o valor do trimestre terminado em março e setembro, respectivamente.

Os dados foram deflacionados a preços de dezembro de 2000 pela variação do índice de inflação oficial IPCA (Índice de Preços ao Consumidor Amplo), destacando-se que, para os dados de despesas administrativas, houve um tratamento diferente por serem uma variável de fluxo e não de estoque como as demais.

Tomou-se como premissa que as despesas administrativas ocorrem de maneira equivalente ao longo do trimestre e, com isso, dividiu-se cada trimestre em três e deflacionouse cada mês pelo respectivo deflator, tomando dezembro de 2000 como base $(=1)$.

Feito isso soma-se o resultado desses três meses resultando no valor final do trimestre deflacionado. Como exemplo segue o seguinte:

(i) Suponha que o dado de despesas administrativas para o trimestre terminado em junho de 2005 seja R\$300.

(ii) Divida esse valor por três, resultando em $\mathrm{R} \$ 100$ para cada um dos meses de abril, maio e junho de 2005. 
(iii) Deflacione os R $\$ 100$ de cada um desses meses pelo respectivo deflator (IPCA acumulado até abril, maio e junho de 2005).

(iv) Some os três resultados, gerando o valor final do trimestre terminado em junho de 2005 deflacionado.

No painel não balanceado são considerados os bancos existentes desde, pelo menos, o ano de 2002, dado que objetivo da análise é verificar o comportamento da produtividade no período anterior e posterior a 2004 (ano de vigência da primeira reforma).

O estudo iniciou com uma lista de 154 bancos, no entanto, muitos deles foram excluídos da amostra por terem a série de dados iniciando após 2002 ou por não terem dados disponíveis para o insumo trabalho ou despesas administrativas, sendo assim, 86 bancos entram na análise para a estimação da função de produção em painel com o aplicativo Stata.

Desse conjunto de bancos buscou-se verificar quais eram os mais intensivos em operações de crédito no período anterior às reformas usando como critério a relação operações de crédito/total do ativo maior ou igual a 50\% na média de março de 2000 a dezembro de 2003 e quais eram os não intensivos, tendo como referência a relação operações de crédito/total do ativo menor que $10 \%$, também no mesmo período anterior às reformas, tendo como premissa o fato que esse conjunto não seria afetado diretamente pelas reformas.

Como resultado tem-se que 25 bancos satisfazem a condição de intensivos em operações de crédito e 15 bancos foram classificados para o grupo de bancos não intensivos.

Além disso, estabeleceu-se um outro grupo, com os cinco maiores bancos do sistema financeiro brasileiro em relação ao ativo total, sendo eles os bancos: Itaú Unibanco, Bradesco, Santander, Banco do Brasil e Caixa Econômica Federal. Importante ressaltar que nenhum desses cinco bancos faz parte concomitantemente de outro grupo.

O produto é medido como o valor total do ativo circulante e realizável a longo prazo, enquanto que o insumo capital é a soma do total de instalações, móveis e equipamentos de uso, imóveis de uso e outros e os insumos intermediários são as despesas administrativas, excluindo-se despesas de pessoal e englobando os gastos com água, energia, gás, manutenção de bens, processamento de dados, comunicação e transporte.

Para o caso de bancos que passaram por um processo de fusão no período considerado (por exemplo, o Itaú com o Unibanco, em 2008) somou-se as contas dos respectivos bancos nos anos anteriores à fusão e para o caso de bancos estrangeiros que ampliaram sua plataforma de operações financeiras ou entraram no Brasil adquirindo algum banco que já existia no país (por exemplo, o Scotiabank adquirindo o Dresdner Bank Brasil, em 2011) 
considera-se, para a formulação da série de dados do banco estrangeiro, a série do banco adquirido até o ano de aquisição.

Para a obtenção dos valores da PTF de cada banco em cada período foi estimada a função de produção de quatro maneiras: por mínimos quadrados ordinários (MQO ou OLS Ordinary Least Squares), por painel com efeitos fixos e pelas metodologias de Levinsohn e Petrin (2003) e Ackerberg, Caves e Frazer (2015).

Logo após essa etapa obtém-se os resíduos, sendo estes uma medida de produtividade total dos fatores, e juntam-se os dados que satisfazem o critério de classificação para os grupos de banco intensivo, não intensivo e top 5.

Por fim, chega-se ao valor da produtividade em cada período e em cada grupo fazendo-se uma média dos resíduos ponderada pelo market share de cada banco, ou seja:

$$
\begin{gathered}
\omega_{t}=\sum_{i=1} \omega_{i t} * s_{i t} \\
s_{i t}=\frac{A T_{i t}}{A T_{t}}
\end{gathered}
$$

onde:

$\omega_{t}=$ valor da produtividade do grupo no período $t$

$\omega_{i t}=$ produtividade do banco i no período $\mathrm{t}$

$S_{i t}=$ market share do banco i no período $\mathrm{t}$

$A T_{i t}=$ ativo total do banco $\mathrm{i}$ no período $\mathrm{t}$

$A T_{t}=$ ativo total do grupo no período $\mathrm{t}$

A tabela 2 a seguir caracteriza as estatísticas descritivas do conjunto total de dados e a tabela 3 mostra a evolução das variáveis em grupos ao longo do período de 2000 a 2014.

Tabela 2: Evolução das variáveis no conjunto de dados

\begin{tabular}{l|ccccc}
\hline & Média & Mediana & Desvio Padrão & Mínimo & Máximo \\
\hline Produto todos os bancos* & $13.425,1$ & 790,8 & $50.314,7$ & 8,9 & $512.581,0$ \\
Capital* & 78,6 & 2,3 & 313,9 & 0,001 & $2.802,0$ \\
Trabalho & 6.043 & 132 & 21.139 & 1 & 132.046 \\
Insumos Intermediários* & 93,6 & 5,8 & 297,7 & 0,025 & $3.586,4$ \\
\hline Obs.* * RS Milhões & & & & &
\end{tabular}


Tabela 3: Evolução das variáveis no conjunto de dados

\begin{tabular}{|c|c|c|c|c|c|c|c|c|}
\hline & \multicolumn{4}{|c|}{ Produto (AC e RLP)* } & \multicolumn{4}{|c|}{$\begin{array}{c}\text { Capital (Imóveis de Uso e Instalações, Móveis e } \\
\text { Equipamentos de Uso e Outros)** }\end{array}$} \\
\hline & $\begin{array}{c}\text { Todos os } \\
\text { Bancos }\end{array}$ & Intensivo & $\begin{array}{c}\text { Não } \\
\text { Intensivo }\end{array}$ & Top 5 & $\begin{array}{c}\text { Todos os } \\
\text { Bancos }\end{array}$ & Intensivo & $\begin{array}{c}\text { Não } \\
\text { Intensivo }\end{array}$ & Top 5 \\
\hline 2000 & 453,4 & 6,5 & 21,7 & 336,4 & $6.336,0$ & 86,4 & 53,4 & $5.595,8$ \\
\hline 2001 & 485,4 & 9,7 & 29,8 & 340,1 & $6.330,5$ & 89,5 & 56,1 & $5.583,2$ \\
\hline 2002 & 516,4 & 11,0 & 30,3 & 371,1 & $5.605,0$ & 82,8 & 46,1 & $4.876,2$ \\
\hline 2003 & 548,5 & 12,4 & 31,4 & 401,9 & $5.001,7$ & 74,2 & 41,3 & $4.314,2$ \\
\hline 2004 & 560,1 & 15,1 & 37,2 & 399,5 & $4.915,0$ & 72,3 & 41,6 & $4.218,2$ \\
\hline 2005 & 642,2 & 17,3 & 53,4 & 447,8 & $4.761,8$ & 75,5 & 44,5 & $3.950,9$ \\
\hline 2006 & 831,9 & 20,8 & 64,5 & 596,0 & $5.276,0$ & 77,3 & 40,2 & $4.490,6$ \\
\hline 2007 & $1.045,6$ & 27,0 & 80,7 & 749,3 & $5.082,8$ & 74,1 & 61,0 & $4.326,9$ \\
\hline 2008 & $1.240,2$ & 28,0 & 77,3 & 927,6 & $5.659,2$ & 68,4 & 61,2 & $4.922,6$ \\
\hline 2009 & $1.457,3$ & 33,3 & 85,3 & $1.146,3$ & $7.606,7$ & 63,9 & 63,8 & $6.671,2$ \\
\hline 2010 & $1.675,8$ & 38,3 & 116,5 & $1.299,1$ & $8.666,1$ & 62,8 & 68,9 & $7.759,4$ \\
\hline 2011 & $1.857,4$ & 42,4 & 124,6 & $1.455,4$ & $9.169,9$ & 55,3 & 85,1 & $8.272,3$ \\
\hline 2012 & $2.017,9$ & 48,2 & 135,4 & $1.592,4$ & $9.021,7$ & 74,9 & 99,0 & $8.081,0$ \\
\hline 2013 & $2.117,5$ & 50,4 & 118,9 & $1.685,2$ & $9.878,9$ & 98,5 & 90,6 & $8.942,9$ \\
\hline 2014 & $2.339,9$ & 46,7 & 124,3 & $1.889,1$ & $10.276,2$ & 112,4 & 133,0 & $9.319,3$ \\
\hline
\end{tabular}

\begin{tabular}{|c|c|c|c|c|c|c|c|c|}
\hline & \multicolumn{4}{|c|}{ Trabalho } & \multicolumn{4}{|c|}{ Insumo Intermediário** } \\
\hline & $\begin{array}{c}\text { Todos os } \\
\text { Bancos }\end{array}$ & Intensivo & $\begin{array}{c}\text { Não } \\
\text { Intensivo }\end{array}$ & Top 5 & $\begin{array}{c}\text { Todos os } \\
\text { Bancos } \\
\end{array}$ & Intensivo & $\begin{array}{c}\text { Não } \\
\text { Intensivo }\end{array}$ & Top 5 \\
\hline 2000 & 1.489 & 1.489 & 1.492 & 290.487 & 84,8 & 84,8 & 80,0 & $3.867,8$ \\
\hline 2001 & 1.914 & 1.914 & 1.583 & 292.175 & 95,9 & 95,9 & 117,8 & $4.034,7$ \\
\hline 2002 & 1.991 & 1.991 & 2.013 & 304.026 & 107,4 & 107,4 & 157,2 & $4.244,8$ \\
\hline 2003 & 2.139 & 2.139 & 1.942 & 307.681 & 120,5 & 120,5 & 148,2 & $4.482,1$ \\
\hline 2004 & 2.280 & 2.280 & 2.123 & 323.130 & 187,4 & 187,4 & 127,6 & $4.680,6$ \\
\hline 2005 & 2.498 & 2.498 & 2.287 & 333.754 & 229,0 & 229,0 & 138,3 & $4.715,6$ \\
\hline 2006 & 2.958 & 2.958 & 2.512 & 358.512 & 261,3 & 261,3 & 247,2 & $4.811,5$ \\
\hline 2007 & 3.523 & 3.523 & 3.139 & 370.019 & 372,1 & 372,1 & 302,2 & $5.165,9$ \\
\hline 2008 & 3.091 & 3.091 & 3.078 & 378.836 & 337,9 & 337,9 & 261,5 & $5.899,3$ \\
\hline 2009 & 3.164 & 3.164 & 2.856 & 442.493 & 601,9 & 601,9 & 426,1 & $7.314,8$ \\
\hline 2010 & 3.583 & 3.583 & 3.237 & 488.792 & 742,1 & 742,1 & 435,3 & $7.868,7$ \\
\hline 2011 & 4.610 & 4.610 & 4.326 & 508.281 & 703,6 & 703,6 & 421,0 & $7.991,8$ \\
\hline 2012 & 5.029 & 5.029 & 4.789 & 514.567 & 511,1 & 511,1 & 659,1 & $8.047,6$ \\
\hline 2013 & 6.058 & 6.058 & 3.647 & 509.463 & 471,6 & 471,6 & 554,2 & $6.445,2$ \\
\hline 2014 & 5.917 & 5.917 & 3.591 & 509.610 & 564,8 & 564,8 & 369,4 & $8.027,5$ \\
\hline
\end{tabular}

*R\$ Bilhões

$* * \mathrm{R} \$$ Milhões

Produto $=$ ativo circulante e realizável a longo prazo

Capital $=$ total instalações, móveis e equipamentos de uso + imobilizado e arrendamento + outros

Insumo Intermediário = Despesas administrativas, que englobam gastos com água, energia, gás, manutenção de bens, processamento de

dados, comunicação, transporte 


\section{RESULTADOS}

Inicialmente foi estimada a função de produção numa regressão em OLS em painel não balanceado com capital e trabalho, sem levar em consideração a questão da endogeneidade e da colinearidade dos insumos.

O problema deste modelo é que ele não distingue entre os vários tipos de bancos que há na base de dados e, combinando-os, nega-se a heterogeneidade e individualidade que pode existir entre os bancos analisados.

Sendo assim, também foi estimada a função de produção num painel com efeito fixo, que permite que sejam analisadas a heterogeneidade e individualidade entre os bancos observados, sendo que o intercepto não varia no tempo.

O termo efeito fixo relata o efeito dentro do modelo, isto é, o intercepto varia entre indivíduos, mas é invariante no tempo.

Logo após esse procedimento buscou-se considerar o efeito da endogeneidade dos insumos, utilizando o insumo intermediário como proxy para a variável não-observada (produtividade), pela metodologia de Levinsohn e Petrin (2003) e considerando também a questão da colinearidade, pelo método proposto em Ackerberg, Caves e Frazer (2015), chegando-se aos seguintes resultados (em log):

Tabela 3: Estimativas dos parâmetros da função de produção

\begin{tabular}{|c|c|c|c|c|c|}
\hline & OLS & $\mathrm{FE}$ & LP & $\mathrm{ACF}$ & $\begin{array}{c}\mathrm{ACF} \\
\left(\ln \_ \text {trab em t-1) }\right.\end{array}$ \\
\hline \multirow[t]{2}{*}{$\ln \_\mathrm{k}$} & 0,3521 & 0,1687 & 0,3889 & 0,3018 & 0,2921 \\
\hline & $(27,43)^{* * *}$ & $(14,43)^{* * *}$ & $(2,57)^{* * *}$ & $(2,40)^{* * *}$ & $(7,47)^{* * *}$ \\
\hline \multirow[t]{2}{*}{ ln_trab } & 0,4269 & 0,3321 & 0,2499 & 0,4132 & 0,4206 \\
\hline & $(31,71)^{* * *}$ & $(26,30)^{* * *}$ & $(2,34)^{* * *}$ & $(2,27)^{* *}$ & $(12,49)^{* * *}$ \\
\hline N. ${ }^{\circ}$ obs: & 5009 & 5009 & 4741 & 4742 & 4742 \\
\hline
\end{tabular}

Há uma série de pontos interessantes a serem discutidos.

As estimativas em OLS e FE tendem a serem viesadas por não considerarem os efeitos da endogeneidade e da colinearidade dos insumos durante a estimação da função de produção. 
De fato, a soma dos coeficientes da regressão em OLS é maior que em todas as outras metodologias, o que faz sentido, pois geralmente seria de se esperar que a escolha dos insumos fosse positivamente correlacionada com $\omega_{i t}$, viesando os retornos de escala para cima. Além disso, é interessante notar que OLS gera a maior estimativa para o $\beta$, o que é consistente com o que há em Levinsohn e Petrin (2003), que afirma que o coeficiente do trabalho em OLS é viesado para cima.

A intuição acerca do viés pode ser derivada da análise da própria estimativa da função de produção com dois insumos, ou seja:

$$
\begin{aligned}
& \hat{\beta}_{l}=\beta_{l}+\frac{\hat{\sigma}_{k, k} \hat{\sigma}_{l, \epsilon}-\hat{\sigma}_{l, k} \hat{\sigma}_{k, \epsilon}}{\hat{\sigma}_{l, l} \hat{\sigma}_{k, k}-\hat{\sigma}^{2}{ }_{l, k}} \\
& \hat{\beta}_{k}=\beta_{k}+\frac{\hat{\sigma}_{l, l} \hat{\sigma}_{k, \epsilon}-\hat{\sigma}_{l, k} \hat{\sigma}_{l, \epsilon}}{\hat{\sigma}_{l, l} \hat{\sigma}_{k, k}-\hat{\sigma}_{l, k}^{2}}
\end{aligned}
$$

em que $\hat{\sigma}_{\mathrm{a}, \mathrm{b}}$ é a covariância entre a e b.

Dado que o denominador é sempre positivo o sinal do viés é determinado pelo numerador.

Se o trabalho responde ao choque de produtividade $\left(\sigma_{l, \epsilon}>0\right)$ e o capital não é correlacionado com o trabalho, então $\hat{\beta}_{l}$ tenderá a ser viesado para cima, mas $\hat{\beta}_{k}$ será não viesado. Caso o trabalho responda ao choque de produtividade e o capital e o trabalho são positivamente correlacionados, um viés negativo no coeficiente do capital pode aparecer. Por fim, se o trabalho e o capital são positivamente correlacionados e a correlação do trabalho com a produtividade é maior que a correlação do capital com a produtividade, o coeficiente do trabalho tenderá a ser superestimado e o coeficiente do capital subestimado.

Com relação ao estimador FE, gerou-se a menor estimativa para o coeficiente do capital, de apenas 0,1687 , sendo que essa metodologia requer o pressuposto de que $\omega_{t}=\omega_{t-1} \forall t$, o que pode ser muito restritivo para um painel de bancos ao longo de 15 anos e talvez por isso, como exposto em Ackerberg, Caves e Frazer (2015), essa técnica não tem funcionado muito bem na prática, resultando geralmente em estimativas baixas de $\beta_{k}$.

Comparando os resultados do ACF com o LP, temos que, enquanto o coeficiente do capital é levemente menor por ACF (0,3018 em relação a 0,3889 por LP) o coeficiente do trabalho é muito menor em LP, o que também está de acordo com o encontrado no estudo de Ackerberg, Caves e Frazer (2015), sendo que os resultados, segundo os autores, são sugestivos de que as estimativas do coeficiente do trabalho no primeiro estágio são viesadas para baixo. 
Como exercício de robustez foi estimada a regressão em ACF com a variável trabalho (em $\log$ ) defasada em um período e os resultados encontrados foram bem próximos dos valores sem essa variável defasada, o que parece um resultado positivo para essa metodologia.

A seguir temos a evolução da produtividade total dos fatores (PTF) para todos os bancos, segundo ACF e LP, sendo que os dados foram obtidos pelo exponencial do log do resíduo na base $e$, gerando valores em nível. Primeiramente é apresentado o resultado agregado de todos os bancos e, logo em seguida, mostra-se a trajetória da PTF separando os grupos intensivo e não intensivo em operações de crédito e a categoria dos cinco maiores bancos brasileiros em relação ao total do ativo (Itaú, Bradesco, Santander, Banco do Brasil e Caixa Econômica Federal). Para os resultados em OLS e em painel com efeitos fixos vide a seção Anexo.

Gráfico 5: PTF todos os bancos (em nível, dez/2003=100)

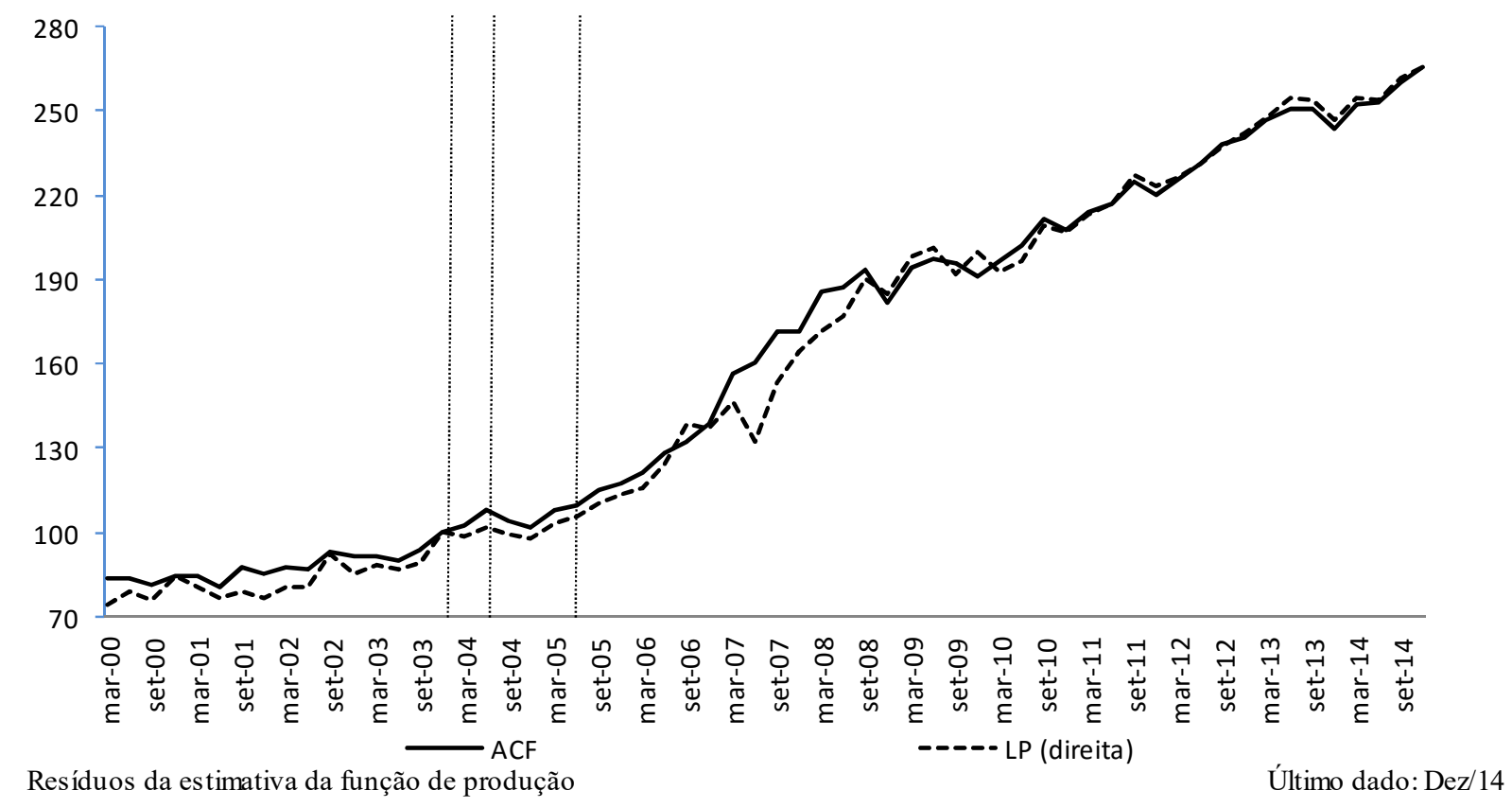

As três linhas verticais representam o momento de ocorrência das reformas, sendo que a primeira representa a introdução do crédito consignado, em dezembro de 2003, a segunda destaca a implementação da alienação fiduciária de automóveis, em agosto de 2004 e a terceira ressalta o momento do estabelecimento da nova lei de falências.

Vale destacar algumas observações. Primeiramente, esses resultados são consistentes com os encontrados em SOUZA-RODRIGUES (2009), sendo que no período pré reformas a PTF oscila sem uma direção bem definida e, após as reformas, é possível observar uma tendência de alta na PTF. 
Assim como no estudo do autor citado anteriormente, não é claro se alguma das reformas isoladamente está causando a aceleração na PTF, dado que não há nada nenhum movimento expressivo que indique isso.

Por outro lado, é razoável deduzir que as reformas levam algum tempo até começarem a surtir efeitos na produtividade, pois mudanças regulatórias demandam tempo até sua consolidação.

Para se ter uma visão mais detalhada acerca dos resultados anteriores, os gráficos 6 e 7 mostram a evolução da PTF dividida em grupos de bancos intensivos e não intensivos em operações de crédito, juntamente com os cinco maiores bancos brasileiros.

Gráfico 6: Evolução da PTF pela regressão em ACF (em nível, dez/2003=100)

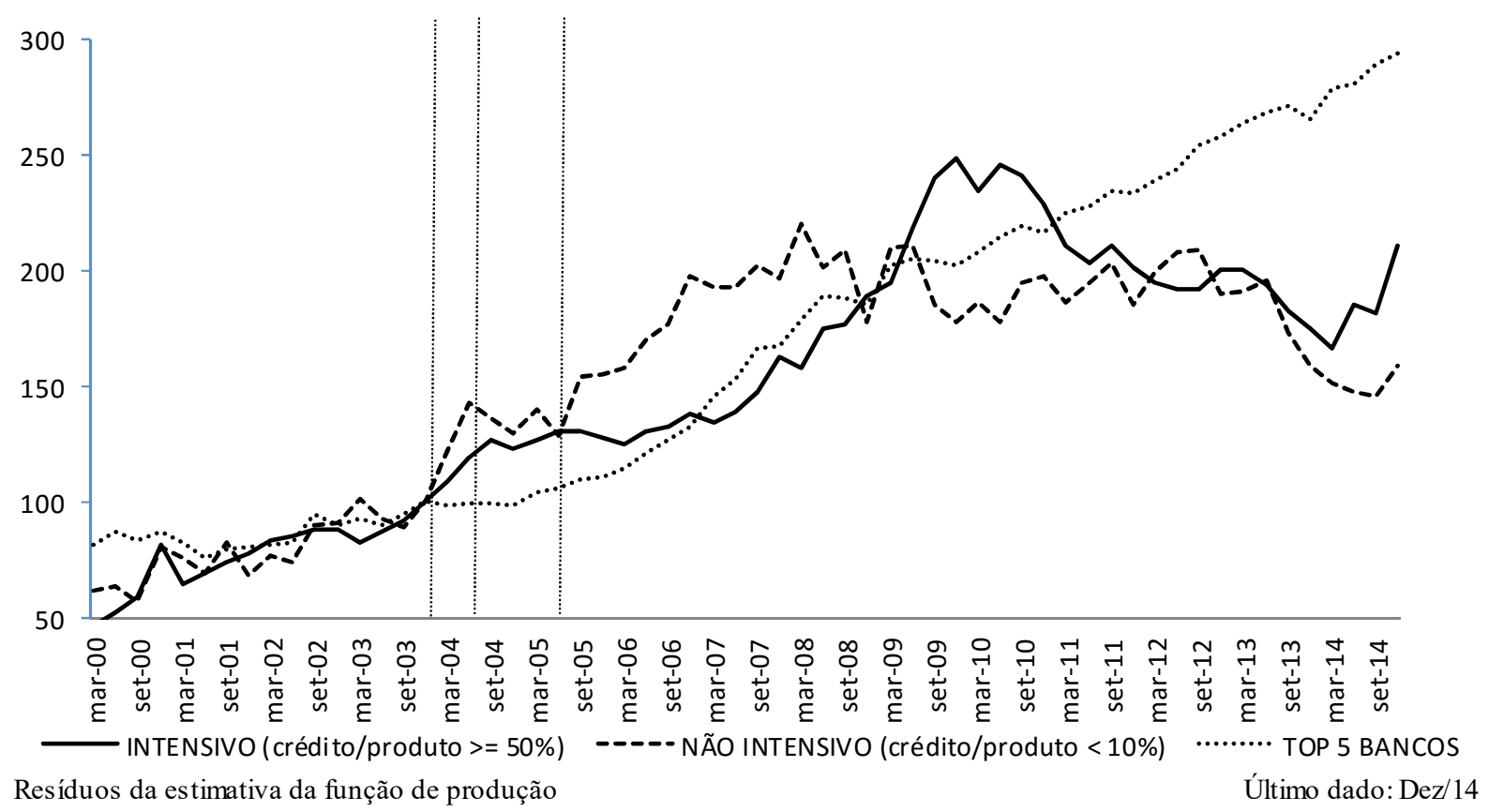

Ao separar os bancos nesses três grupos observam-se resultados interessantes.

Primeiramente ressalta-se que, pela metodologia ACF, o crescimento da PTF, para os bancos intensivos em crédito, acontece sem grandes oscilações no período após as reformas até o final de 2009, mantendo estabilidade em 2010 para entrar num movimento de baixa até o início de 2014, para só então retomar força para voltar a subir.

Para o grupo de bancos não intensivos em operações de crédito observa-se uma rápida alta na PTF após as reformas até 2006, movimento que pode não estar relacionado propriamente às reformas, pois este grupo já mostrava uma tendência de alta antes da introdução do crédito consignado. 
Também é interessante observar que, após 2006 a produtividade começou a oscilar sem uma tendência definida até 2013, o que reforça o pressuposto de que as reformas não teriam grande impacto para os bancos não intensivos em operações de crédito.

Para os bancos do grupo Top 5 nota-se certa estabilidade na trajetória da PTF no período pré e entre reformas, passando a apresentar uma tendência de alta após 2005, valendo destacar que esse movimento segue sem grandes oscilações durante todo o período.

Gráfico 7: Evolução da PTF pela regressão em LP (em nível, dez/2003=100)

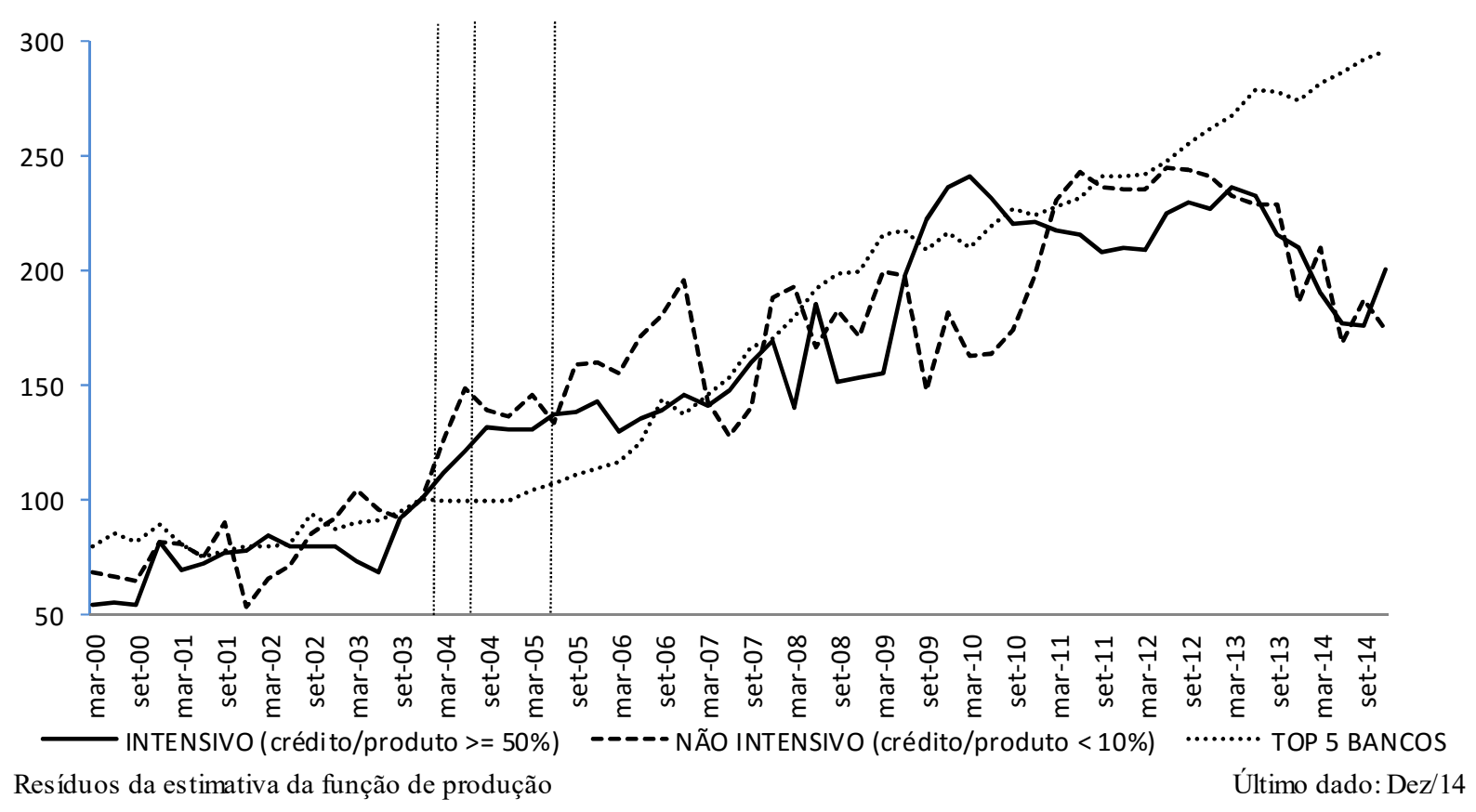

Pela metodologia LP observa-se maiores ruídos na trajetória da PTF, sendo que, de maneira similar ao que acontece em ACF, os bancos intensivos apresentam crescimento da produtividade após as reformas até o final de 2009, passando por um movimento de baixa até o início de 2014.

Para os bancos não intensivos, da mesma forma como em $\mathrm{ACF}$, há uma rápida alta após as reformas até 2006, mas a partir daí passa a oscilar sem uma tendência definida até 2010 e, diferentemente da metodologia anterior, há uma alta até 2011, passando por um período de estabilidade até o final de 2012 para entrar num movimento de baixa.

Para os bancos do grupo Top 5 o movimento da PTF é bastante similar ao que ocorre na estimação em ACF.

A seguir é apresentado um quadro resumo com os dados de crescimento médio anual da PTF dividido em 4 períodos. 
Tabela 6: Crescimento Médio Anual da PTF

\begin{tabular}{|c|c|c|c|c|c|c|c|c|}
\hline & \multicolumn{4}{|c|}{$\mathrm{ACF}$} & \multicolumn{4}{|c|}{ LP } \\
\hline & $\begin{array}{c}\text { Todos } \\
\text { os } \\
\text { bancos }\end{array}$ & Intensivos & $\begin{array}{c}\text { Não } \\
\text { Intensivos }\end{array}$ & Top 5 & \begin{tabular}{|c} 
Todos \\
os \\
bancos \\
\end{tabular} & Intensivos & $\begin{array}{c}\text { Não } \\
\text { Intensivos }\end{array}$ & Top 5 \\
\hline $\begin{array}{l}\text { Pré Reformas } \\
\text { (2000-2003) }\end{array}$ & $5,8 \%$ & $7,0 \%$ & $7,3 \%$ & $4,6 \%$ & $5,6 \%$ & $7,3 \%$ & $7,2 \%$ & $4,2 \%$ \\
\hline $\begin{array}{l}\text { Pós Reformas } \\
(2004-2014)\end{array}$ & $9,3 \%$ & $7,0 \%$ & $4,3 \%$ & $10,3 \%$ & $9,3 \%$ & $6,5 \%$ & $5,1 \%$ & $10,3 \%$ \\
\hline $\begin{array}{l}\text { Reformas até } \\
\text { Crise (2004- } \\
\text { 2009) }\end{array}$ & $11,4 \%$ & $16,4 \%$ & $10,0 \%$ & $12,5 \%$ & $12,2 \%$ & $15,4 \%$ & $10,5 \%$ & $13,5 \%$ \\
\hline $\begin{array}{l}\text { Pós Crise } \\
(2010-2014)\end{array}$ & $6,8 \%$ & $-3,2 \%$ & $-2,2 \%$ & $7,7 \%$ & $5,8 \%$ & $-3,2 \%$ & $-0,9 \%$ & $6,5 \%$ \\
\hline $\begin{array}{l}\text { Todo Período } \\
(2000-2014)\end{array}$ & $8,5 \%$ & $7,0 \%$ & $4,9 \%$ & $9,0 \%$ & $8,5 \%$ & $6,7 \%$ & $5,6 \%$ & $8,9 \%$ \\
\hline
\end{tabular}

Verifica-se pelo quadro acima que após as reformas o conjunto agregado dos bancos passou a apresentar crescimento médio de $9,3 \%$ a.a. da PTF, ante 5,8\% no período anterior às reformas, segundo a metodologia proposta por ACF.

Mais interessante é observar o resultado para os bancos intensos e não intensivos. Apesar de a taxa de crescimento médio da PTF para o primeiro grupo após as reformas como um todo (2004-2014) ter sido a mesma que antes das reformas (7,0\% a.a.) o crescimento médio da produtividade foi de 16,4\% a.a. no período até a crise financeira mundial (2004-2009), enquanto que o segundo grupo, mostrou uma taxa média de $10 \%$ a.a. e, no período pós crise, ambos os grupos passaram a apresentar taxas médias negativas de crescimento da PTF.

O crescimento da produtividade do grupo Top 5 é bastante próximo ao verificado para o grupo agregado, o que era esperado, dado que os bancos são ponderados pelo market share e os cincos maiores bancos do sistema financeiro brasileiro juntamente representam cerca de $75 \%$ a $80 \%$ do mercado em termos do ativo total.

Por fim, é apresentada a decomposição da produtividade dos bancos ao longo do tempo nas tabelas 4 e 5, sendo que, como dito anteriormente, a produtividade agregada é calculada como a média ponderada dos resíduos para cada período, em que os pesos são dados pelo market share de cada banco em cada período. 
Sendo assim, seguindo Olley e Pakes (1996), foi decomposta a média ponderada pela soma da média simples, e o termo de covariância entre produtividade e produto, ou seja:

$$
p_{t}=\sum_{i=1} s_{i t} * p_{i t}=\bar{p}+\sum_{i=1} \Delta s_{i t} * \Delta p_{i t}
$$

em que $\bar{p}$ é a média simples dos resíduos, que também pode ser entendida como a produtividade a nível do banco não ponderada; $s_{i t}$ é o market share do banco i no período t; e $\sum_{i=1} \Delta s_{i t} * \Delta p_{i t}$ é o termo de covariância entre a PTF e o produto e, quanto maior esse termo, maior a parcela do produto que vai para bancos mais produtivos.

Os dados a seguir estão normalizados em relação à PTF Ponderada de $2003(=100)$ e a coluna Realocação é a diferença da PTF Ponderada e a PTF a Nível do Banco, que é simplesmente a produtividade não ponderada.

Tabela 4: Decomposição da Produtividade

\begin{tabular}{c|ccc|ccc}
\hline & \multicolumn{2}{|c|}{ INTENSIVO (crédito/produto $>=\mathbf{5 0 \% )}$} & \multicolumn{3}{|c}{ NãO INTENSIVO (crédito/produto $<$ 10\%) } \\
& $\begin{array}{c}\text { PTF Ponderada } \\
\text { (ACF) }\end{array}$ & $\begin{array}{c}\text { PTF a Nível do } \\
\text { Banco (ACF) }\end{array}$ & $\begin{array}{c}\text { Realocação } \\
\mathbf{( \% )}\end{array}$ & $\begin{array}{c}\text { PTF Ponderada } \\
\text { (ACF) }\end{array}$ & $\begin{array}{c}\text { PTF a Nível do } \\
\text { Banco (ACF) }\end{array}$ & $\begin{array}{c}\text { Realocação } \\
\text { (\%) }\end{array}$ \\
\hline 2000 & 96,2 & 89,8 & 6,5 & 96,5 & 93,2 & 3,4 \\
2001 & 98,2 & 90,8 & 7,4 & 97,6 & 91,4 & 6,1 \\
2002 & 99,1 & 92,4 & 6,7 & 99,4 & 91,2 & 8,1 \\
2003 & 100,0 & 93,2 & 6,8 & 100,0 & 92,2 & 7,8 \\
2004 & 101,4 & 94,4 & 7,0 & 101,6 & 92,7 & 8,9 \\
2005 & 101,7 & 94,6 & 7,0 & 102,8 & 93,3 & 9,5 \\
2006 & 102,2 & 95,2 & 7,0 & 104,4 & 93,7 & 10,6 \\
2007 & 103,3 & 96,5 & 6,8 & 104,3 & 95,0 & 9,3 \\
2008 & 104,4 & 96,2 & 8,2 & 103,7 & 94,1 & 9,6 \\
2009 & 106,7 & 97,4 & 9,2 & 103,7 & 95,5 & 8,2 \\
2010 & 105,3 & 97,0 & 8,3 & 104,4 & 96,6 & 7,8 \\
2011 & 104,8 & 97,7 & 7,2 & 104,0 & 96,4 & 7,6 \\
2012 & 104,8 & 97,6 & 7,2 & 104,1 & 95,0 & 9,1 \\
2013 & 103,9 & 96,7 & 7,1 & 103,0 & 96,0 & 7,0 \\
2014 & 103,0 & 96,8 & 6,2 & 103,0 & 96,0 & 6,9 \\
\hline
\end{tabular}

Desses resultados é interessante observar a maior realocação do produto de bancos menos produtivos para bancos mais produtivos durante a crise financeira mundial de 2008 para o grupo de bancos intensivos em crédito, o que faz sentido, dado que nesse período muitos bancos chegaram à falência por conta da incerteza no mercado e da menor disponibilidade de crédito, que pode ter contribuído para que os bancos mais produtivos tenham ganhando mais espaço nesse ambiente mais competitivo. 
Tabela 5: Decomposição da Produtividade

\begin{tabular}{r|rrc}
\hline & $\begin{array}{c}\text { TOP 5 BANCOS } \\
\text { PTF Ponderada } \\
\text { (ACF) }\end{array}$ & $\begin{array}{c}\text { PTF Nível do } \\
\text { Banco (ACF) }\end{array}$ & $\begin{array}{c}\text { Realocação } \\
\text { (\%) }\end{array}$ \\
\hline 2000 & 98,4 & 96,0 & 2,4 \\
2001 & 98,5 & 95,5 & 2,9 \\
2002 & 99,2 & 96,0 & 3,2 \\
2003 & 100,0 & 96,8 & 3,2 \\
2004 & 99,9 & 97,4 & 2,4 \\
2005 & 100,7 & 98,3 & 2,4 \\
2006 & 101,9 & 101,9 & 0,0 \\
2007 & 103,6 & 103,5 & 0,1 \\
2008 & 104,3 & 103,8 & 0,5 \\
2009 & 104,9 & 104,7 & 0,2 \\
2010 & 105,4 & 105,1 & 0,2 \\
2011 & 105,9 & 105,7 & 0,2 \\
2012 & 106,6 & 106,3 & 0,3 \\
2013 & 106,8 & 106,5 & 0,3 \\
2014 & 107,5 & 107,3 & 0,2 \\
\hline
\end{tabular}




\section{CONCLUSÃO}

Este trabalho estimou a produtividade total dos fatores (PTF) para o mercado bancário brasileiro ao longo de março de 2000 a dezembro 2014 através das metodologias propostas por Levinsohn e Petrin (2003) e de Ackerberg, Caves e Frazer (2015) para controlar problemas de endogeneidade e colinearidade que surgem por conta da variável não observada (produtividade) e da escolha dos insumos. O objetivo foi verificar se as reformas institucionais ocorridas ao longo da primeira metade dos anos 2000 produziram impacto no crescimento da produtividade. Tais reformas agiram no sentido de (i) diminuir o risco de inadimplência nos empréstimos, com a implementação do crédito consignado; (ii) reformular procedimentos de modo a melhorar a execução de garantias e reduzir a insegurança jurídica, com a introdução da alienação fiduciária de automóveis; (iii) aumentar os diretos dos credores, com a aprovação da lei de falências; (iv) reduzir a assimetria de informação, com o estabelecimento do Sistema de Informações de Crédito do Banco Central (SCR).

Os resultados mostram que (i) a produtividade agregada dos bancos oscilava sem direção definida no período anterior às reformas, mas mostraram um crescimento após as reformas; (ii) bancos intensivos em operações de crédito apresentaram ganho de produtividade de 7,0\% a.a. após as reformas, totalizando $110,7 \%$ no período de 2004 a 2014, o que representa um crescimento bem mais expressivo que os $4,3 \%$ a.a. para os bancos não intensivos, totalizando ganho de 58,9\% após as reformas; e (iii) maior realocação do produto de bancos menos produtivos para bancos mais produtivos durante a crise financeira mundial de 2008.

A principal limitação deste trabalho é a dificuldade em isolar os efeitos de cada reforma, dado que mudanças regulatórias envolvem fatores qualitativos que geram impactos difíceis de serem mensurados consistentemente. 


\section{REFERÊNCIAS}

ACKERBERG, Daniel A et al. "Structural Identification of Production Functions" Econometrica, Vol. 83, No. 6, 2411-2451, 2015

AMENDOLARA, César. "Alienação fiduciária como instrumento de fomento à concessão de crédito”, In: Waisberg, Ivo (Coord.) e Fontes, Marcos Rolim Fernandes (Coord.). Contratos Bancários. São Paulo: Quartier Latin, 2006

ARAÚJO, Aloisio; FUNCHAL, Bruno. “A nova lei de falências brasileira: Primeiros impactos”, Brazilian Journal of Political Economy, 29(3):1-20, 2009

ASSUNCAO, Juliano et al. "Repossession and the Democratization of Credit", Review of Financial Studies, 27(9): 2661-2689, 2014.

FREITAS, Maria Cristina Penido de; PRATES, Daniela Magalhães. "O mercado de crédito no Brasil: Tendências recentes", Panorama das economias internacional e brasileira: dinâmica e impactos da crise global, São Paulo, FUNDAP, 215-234, 2009.

LEVINE, Ross; DEMIRGÜÇ-KUNT, Asli. "Finance, Financial Sector Policies, and LongRun Growth”, World Bank, 2008.

LEVINSOHN, James; PRETIN, Amil. "Estimating production functions using inputs to control for unobservables”, Review of Economic Studies, 70, 317-342, 2003.

LISBOA, Marcos de Barros; PESSOA, Samuel de Abreu. "Uma história sobre dois países (por enquanto)", Insper Policy paper n. ${ }^{\circ} 06,2003$.

MADEIRA, Gabriel Abreu et al. "Occupational Choices and Limited Commitment: Inferential evidence from the availability of new credit instruments", 2010.

NAKANE, Márcio Issao; WEINTRAUB, Daniela Baumohl. "Bank privatization and productivity: Evidence for Brazil”, Journal of Banking \& Finance, 29, 2259-2289, 2005. 
OLLEY, G.; PAKES, A. "The dynamics of productivity in the telecommunications equipment industry”, Econometrica, 64, 1263-1297, 1996.

PONTICELLI, Jacopo. "Court Enforcement and Firm Productivity: Evidence from a Bankruptcy Reform in Brazil", University of Chicago, 2014.

RODRIGUES, Eduardo. A. S et al. "O efeito da consignação em folha nas taxas de juros dos empréstimos pessoais”, Banco Central do Brasil, Trabalhos para discussão n. ${ }^{\circ}$ 108, 2006.

ROYSTER, Sara E. "Improved measures of commercial banking output and productivity", Monthly Labor Review, Bureau of Labor Statistics, 2012.

SOUZA-RODRIGUES, Eduardo. A. "The Effects of Institutional Changes on Bank Productivity: The Brazilian Case”, Yale University, 2009.

WOOLDRIDGE, Jeffrey. “On Estimating Firm-level Production Functions Using Proxy Variables to Control for Unobservables”, Michigan State University, 2005. 


\section{APÊNDICE}

Lista dos bancos incluídos na amostra

\begin{tabular}{|c|c|c|c|}
\hline Nome da Instituição & CNPJ & Crédito* & Segmento \\
\hline Banco A.J. Renner S.A. & 92.874 .270 & $72 \%$ & Banco Múltiplo \\
\hline Banco Abc Brasil S.A. & 28.195 .667 & $46 \%$ & Banco Múltiplo \\
\hline Banco ABN Amro S.A. & 03.532 .415 & $36 \%$ & Banco Múltiplo \\
\hline Banco Alfa S.A. & 03.323 .840 & $3 \%$ & Banco Comercial \\
\hline Banco Arbi S.A. & 54.403 .563 & $10 \%$ & Banco Comercial \\
\hline Banco Barclays S.A. & 61.146 .577 & $19 \%$ & Banco Múltiplo \\
\hline Banco BBM S/A & 15.114 .366 & $16 \%$ & Banco Múltiplo \\
\hline Banco BMG S.A. & 61.186 .680 & $63 \%$ & Banco Múltiplo \\
\hline Banco BNP Paribas Brasil S.A. & 01.522 .368 & $12 \%$ & Banco Múltiplo \\
\hline Banco Bonsucesso S.A. & 71.027 .866 & $70 \%$ & Banco Múltiplo \\
\hline Banco Bracce S.A. & 48.795 .256 & $0 \%$ & Banco Comercial \\
\hline Banco Bradesco S.A. & 60.746 .948 & $34 \%$ & Banco Múltiplo \\
\hline Banco BRJ S.A. & 27.937 .333 & $50 \%$ & Banco Múltiplo \\
\hline Banco BTG Pactual S.A. & 30.306 .294 & $1 \%$ & Banco Múltiplo \\
\hline Banco Cacique S.A. & 33.349 .358 & $46 \%$ & Banco Múltiplo \\
\hline Banco Capital S.A. & 15.173 .776 & $35 \%$ & Banco Múltiplo \\
\hline Banco Cargill S.A. & 03.609 .817 & $26 \%$ & Banco Múltiplo \\
\hline Banco Cedula S.A. & 33.132 .044 & $66 \%$ & Banco Múltiplo \\
\hline Banco Cifra S.A. & 62.421 .979 & $59 \%$ & Banco Múltiplo \\
\hline Banco Citibank S.A. & 33.479 .023 & $25 \%$ & Banco Múltiplo \\
\hline Banco Classico S.A. & 31.597 .552 & $0 \%$ & Banco Múltiplo \\
\hline Banco CNH Industrial Capital S.A. & 02.992 .446 & $91 \%$ & Banco Múltiplo \\
\hline $\begin{array}{l}\text { Banco Cooperativo Do Brasil S.A. - } \\
\text { Bancoob }\end{array}$ & 02.038 .232 & $34 \%$ & $\begin{array}{l}\text { Banco Comercial } \\
\text { Cooperativo }\end{array}$ \\
\hline Banco Cooperativo Sicredi S.A. & 01.181 .521 & $29 \%$ & $\begin{array}{l}\text { Banco Múltiplo } \\
\text { Cooperativo }\end{array}$ \\
\hline Banco Crédit Agricole Brasil S.A. & 75.647 .891 & $11 \%$ & Banco Múltiplo \\
\hline Banco Credit Suisse (Brasil) S.A. & 32.062 .580 & $0 \%$ & Banco Múltiplo \\
\hline Banco Da Amazônia S.A. & 04.902 .979 & $12 \%$ & Banco Comercial \\
\hline Banco Daycoval S.A. & 62.232 .889 & $45 \%$ & Banco Múltiplo \\
\hline Banco De Lage Landen Brasil S.A. & 05.040 .481 & $61 \%$ & Banco Múltiplo \\
\hline
\end{tabular}


Banco De Tokyo-Mitsubishi Ufj Brasil S.A.

Banco Do Brasil S.A.

Banco Do Estado De Sergipe S.A.

Banco Do Estado Do Pará S.A.

Banco Do Estado Do Rio Grande Do Sul S.A.

Banco Do Nordeste Do Brasil S.A.

Banco Fator S.A.

Banco Fibra S.A.

Banco Ficsa S.A.

Banco Guanabara S.A.

Banco Honda S.A.

Banco Industrial Do Brasil S.A.

Banco Indusval S.A.

Banco Intercap S.A.

Banco J.P. Morgan S.A.

Banco John Deere S.A.

Banco KEB Do Brasil S.A.

Banco Luso Brasileiro S.A.

Banco Máxima S.A.

Banco Maxinvest S.A.

Banco Mizuho Do Brasil S.A.

Banco Modal S.A.

Banco Opportunity De Investimento S.A.

Banco Original S.A.

Banco Ourinvest S.A.

Banco Pan S.A.

Banco Pecunia S.A.

Banco Pine S.A.

Banco Porto Real De Investimentos S.A

Banco Pottencial S.A.

Banco PSA Finance Brasil S.A.

Banco Rabobank International Brasil S.A.
60.498 .557

00.000.000 23\% Banco Múltiplo

13.009.717

04.913 .711

92.702 .067

07.237 .373

33.644 .196

58.616 .418

61.348 .538

31.880 .826

03.634 .220

31.895 .683

61.024 .352

58.497 .702

33.172 .537

91.884 .981

02.318 .507

59.118 .133

33.923 .798

80.271 .455

61.088 .183

30.723 .886

33.857 .830

92.894 .922

78.632 .767

59.285 .411

60.850 .229

62.144 .175

40.429 .946

00.253 .448

03.502 .961

01.023 .570
$29 \%$

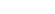

26\% Banco Múltiplo

$22 \%$ Banco Múltiplo

29\% Banco Múltiplo

47\% Banco Múltiplo

0\% Banco Múltiplo

13\% Banco Múltiplo

67\% Banco Múltiplo

30\% Banco Múltiplo

$70 \%$ Banco Múltiplo

$50 \%$ Banco Múltiplo

28\% Banco Múltiplo

49\% Banco Múltiplo

2\% Banco Múltiplo

87\% Banco Múltiplo

$38 \%$ Banco Comercial

61\% Banco Múltiplo

$6 \%$ Banco Comercial

$78 \%$ Banco Múltiplo

$7 \%$ Banco Múltiplo

41\% Banco Múltiplo

$0 \% \quad$ Banco de Investimento

55\% Banco Múltiplo

51\% Banco Múltiplo

$70 \%$ Banco Múltiplo

57\% Banco Múltiplo

61\% Banco Múltiplo

49\% Banco de Investimento

$57 \%$ Banco Comercial

86\% Banco Múltiplo

22\% Banco Múltiplo 
Banco Rendimento S.A.

Banco Ribeirão Preto S.A.

Banco Rodobens S.A.

Banco Santander (Brasil) S.A.

Banco Semear S.A.

Banco Societe Generale Brasil S.A.

Banco Sofisa S.A.

Banco Sumitomo Mitsui Brasileiro S.A.

Banco Triângulo S.A.

Banco Tricury S.A.

Banco Volkswagen S.A.

Banco Votorantim S.A.

Banco VR S.A.

Banestes S.A. Banco Do Estado Do

Espirito Santo

BANIF - Banco Internacional Do Funchal (Brasil), S.A.

Bank Of America Merrill Lynch Banco Múltiplo S.A.

BPN Brasil Banco Múltiplo S.A.

BRB - Banco De Brasília S.A.

Caixa Econômica Federal

Deutsche Bank S.A. - Banco Alemão

HSBC Bank Brasil S.A. - Banco Múltiplo

Itaú Unibanco S.A.

Novo Banco Continental S.A. - Banco Múltiplo

Scotiabank Brasil S.A. Banco Múltiplo
Banco Safra S.A.

\begin{tabular}{|c|c|c|}
\hline 68.900 .810 & $23 \%$ & Banco Comercial \\
\hline 00.517 .645 & $79 \%$ & Banco Múltiplo \\
\hline 33.603 .457 & $4 \%$ & Banco Múltiplo \\
\hline 58.160 .789 & $30 \%$ & Banco Múltiplo \\
\hline 90.400 .888 & $20 \%$ & Banco Múltiplo \\
\hline 00.795 .423 & $10 \%$ & Banco Múltiplo \\
\hline 61.533 .584 & $8 \%$ & Banco Múltiplo \\
\hline 60.889 .128 & $40 \%$ & Banco Múltiplo \\
\hline 60.518 .222 & $28 \%$ & Banco Múltiplo \\
\hline 17.351.180 & $74 \%$ & Banco Múltiplo \\
\hline 57.839 .805 & $48 \%$ & Banco Múltiplo \\
\hline 59.109 .165 & $89 \%$ & Banco Múltiplo \\
\hline 59.588 .111 & $4 \%$ & Banco Múltiplo \\
\hline 78.626 .983 & $15 \%$ & Banco Múltiplo \\
\hline 28.127 .603 & $27 \%$ & Banco Múltiplo \\
\hline 33.884 .941 & $10 \%$ & Banco Múltiplo \\
\hline 62.073 .200 & $0 \%$ & Banco Múltiplo \\
\hline 61.033 .106 & $24 \%$ & Banco Múltiplo \\
\hline 00.000 .208 & $38 \%$ & Banco Múltiplo \\
\hline 00.360 .305 & $26 \%$ & $\begin{array}{l}\text { Caixa Econômica } \\
\text { Federal }\end{array}$ \\
\hline 62.331 .228 & $9 \%$ & Banco Múltiplo \\
\hline 01.701 .201 & $29 \%$ & Banco Múltiplo \\
\hline 60.701 .190 & $28 \%$ & Banco Múltiplo \\
\hline 74.828 .799 & $53 \%$ & Banco Múltiplo \\
\hline 29.030 .467 & $35 \%$ & Banco Múltiplo \\
\hline
\end{tabular}

*Média da razão da conta de operações de crédito/ativo total no período anterior às reformas, de março de 2000 a dezembro de 2003 


\section{ANEXO}

Gráfico 8: Evolução da PTF pela regressão em OLS (em nível, dez/2003=100)

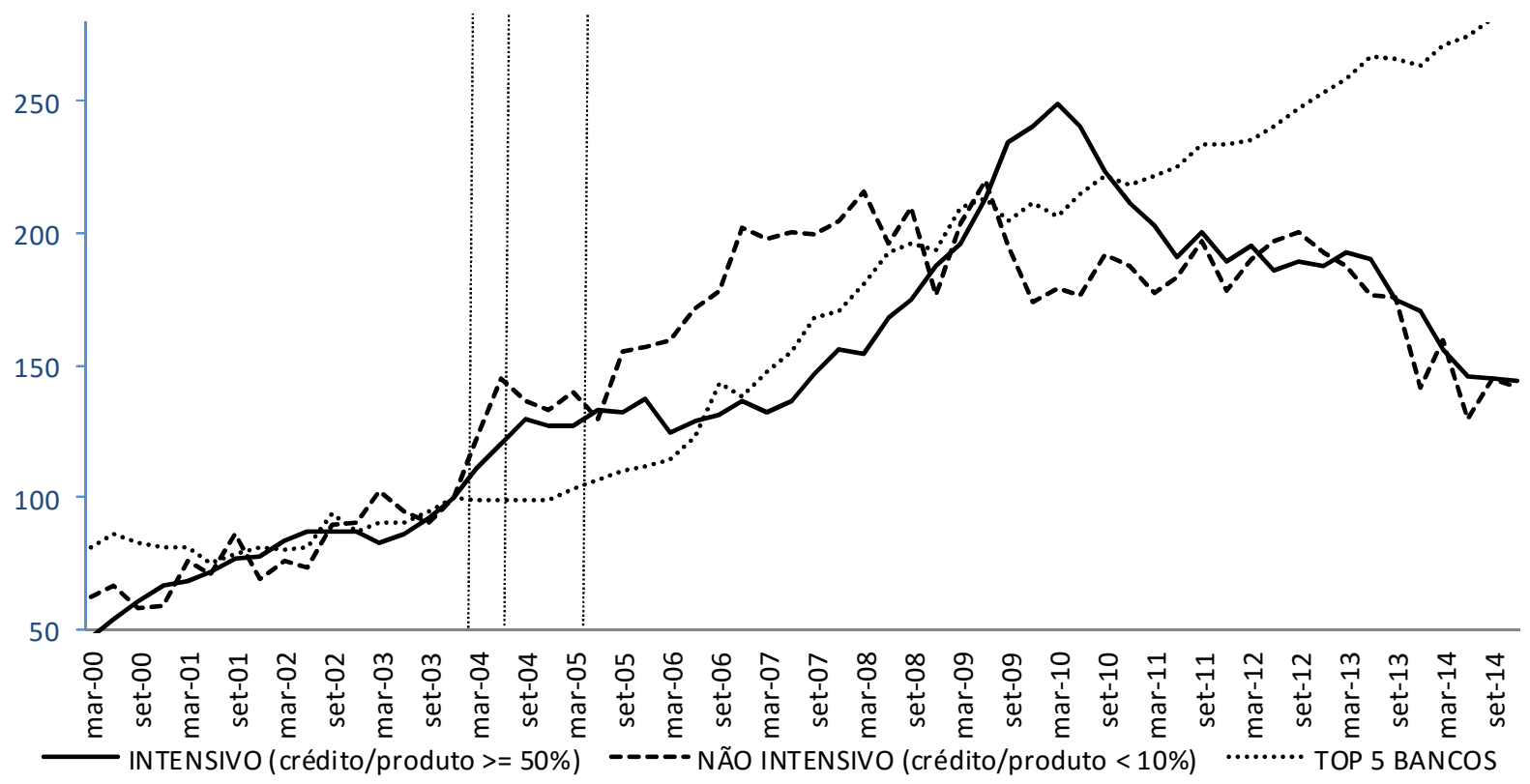

Resíduos da estimativa da função de produção

Gráfico 9: Evolução da PTF pela regressão em FE (em nível, dez/2003=100)

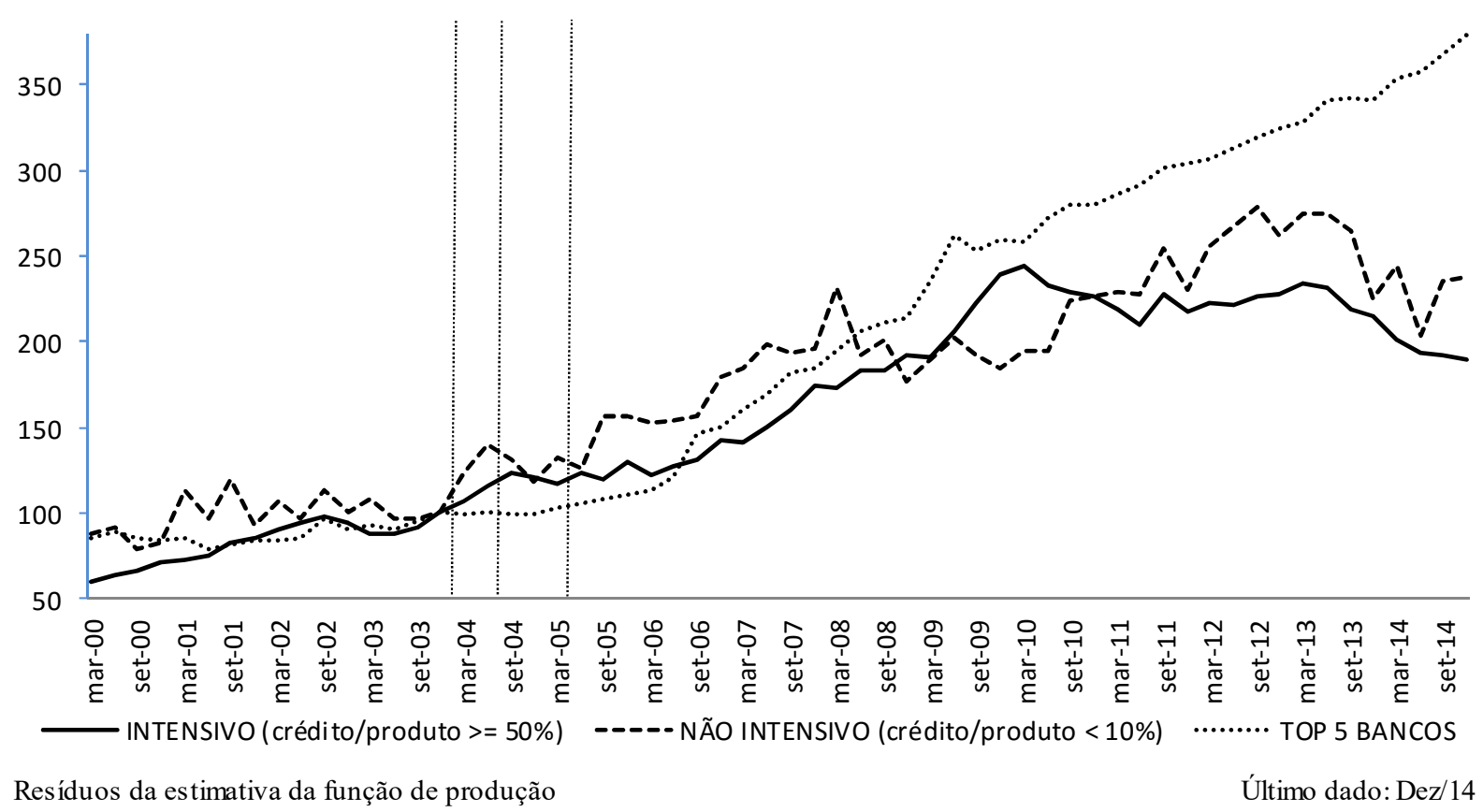

